\title{
Orientation and Wayfinding: Measuring Visibility
}

\section{Contents}

3.1 Isovist Analyses

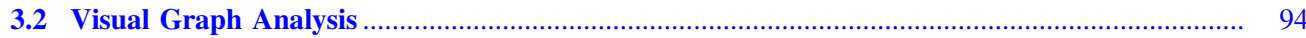

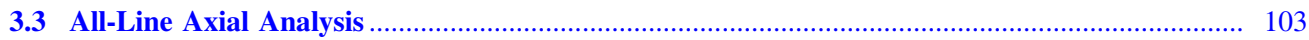

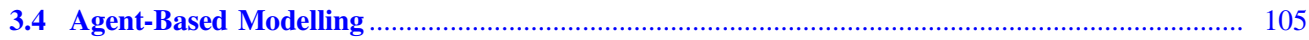

3.5 Conclusion: Some Common Errors to Be Aware Of ............................................................... 108

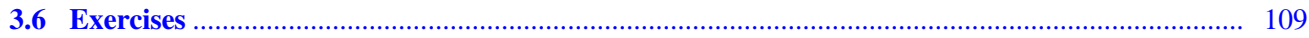

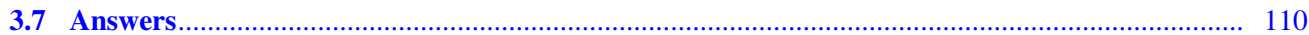

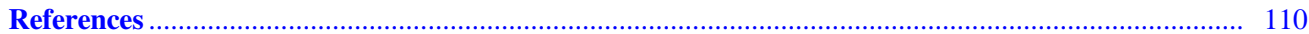

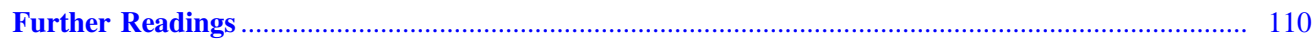

\section{Abstract}

In this chapter, we explain how the analytical logic of space syntax is applied for visibility analysis. In the previous chapter, the focus was on presenting all public spaces as axial sightlines. The individual axial line is a one-dimensional (1D) representation of public space and is useful for analysing the interrelationship of public spaces on a citywide scale. At the neighbourhood scale, a two-dimensional (2D) representation of spatial elements can be useful. In particular, the public realm, such as public squares, parks, and wide streets, benefits from a 2D spatial analysis with a visual field using a raster-based as well as an all-line modelling approach. In order to explain visibility analysis in space syntax, we start with the well-known 2D geographical visibility analysis 'isovist' as a field of vision. We build upon and explain visibility point-depth analysis and visual graph analysis. Further, we demonstrate how the simple point-depth calculations contribute to a theory on space and urban centrality. In addition, we discuss 3D isovists. Furthermore, we also demonstrate and discuss the use of the all-line analysis. Finally, we expound upon agent-based modelling. Exercises are provided at the end of this chapter.

\section{Keywords}

Visibility • Wayfinding • Isovist • Visual graph analysis • All-line analysis • Agent-based modelling

\section{Key Concepts}

Orientation and navigation • Wayfinding • Convex space • Two-dimensional (2D) representation of space • Visual field • Through vision • All-lines 


\section{Learning Objectives}

After studying this chapter, you will

- be familiar with the concept of visual fields;

- have knowledge about how to calculate spatial integration for visual fields;

- be able to conduct an isovist analysis, visual graph analysis, and through vision analysis;

- have an understanding of the all-line axial map and how to create it;

- have knowledge about agent-based modelling using visual fields and be capable of creating an agent-based model; and

- be able to critically reflect on different concepts and analysis techniques related to visibility, orientation, and navigation, including wayfinding for different spatial settings.

\subsection{Isovist Analyses}

Visual orientation is decisive in how we orientate ourselves and thus navigate through the built environment. When manoeuvring through an area we are not familiar with, we aspire to get a visual overview of the spaces we are moving through. Often, a panoptical view field of $180^{\circ}$ is appropriate for most people when cruising through cities. Contrarily, a guerrilla soldier on foot has to act fast in every spatial direction in each space. The soldier is in need of an immediate $360^{\circ}$ overview in all directions of every space they enter. These $360^{\circ}$ turns have to be made for every step the guerrilla soldier takes because the visual field can change significantly with every step taken. Likewise, a sniper with their static position has to regularly take a $360^{\circ}$ overview of their location to ensure avoiding an ambush. The panoptical view from a certain location is called an 'isovist'.

C. R. V. Tandy is acknowledged to have coined the term 'isovist' in 1967 (Tandy 1967). The most well-known definition of an isovist is from M. L. Benedikt, who also introduced a set of analytical measurements of isovist properties. Benedikt $(1979$, p. 47) explains that an isovist is "(...) the set of all points visible from a given vantage point in space and with respect to an environment". An isovist can be briefly explained as a visual record of what can be seen in a $360^{\circ}$ angle from a given location. The visual record is taken at average eye height. Isovists describe the space from the viewpoint of individuals as they perceive, interact with, and move through space (Turner et al. 2001). For landscape architecture, urban planning, and military science, a similar concept of 'viewshed' is applied.

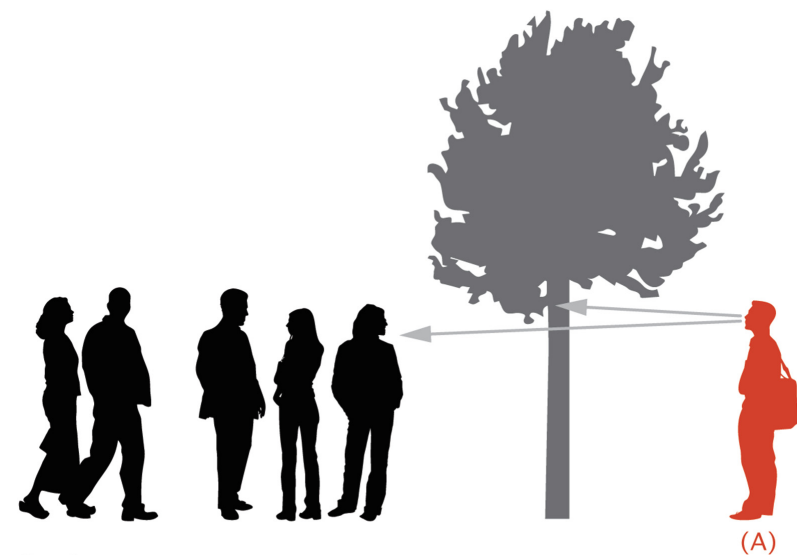

Section

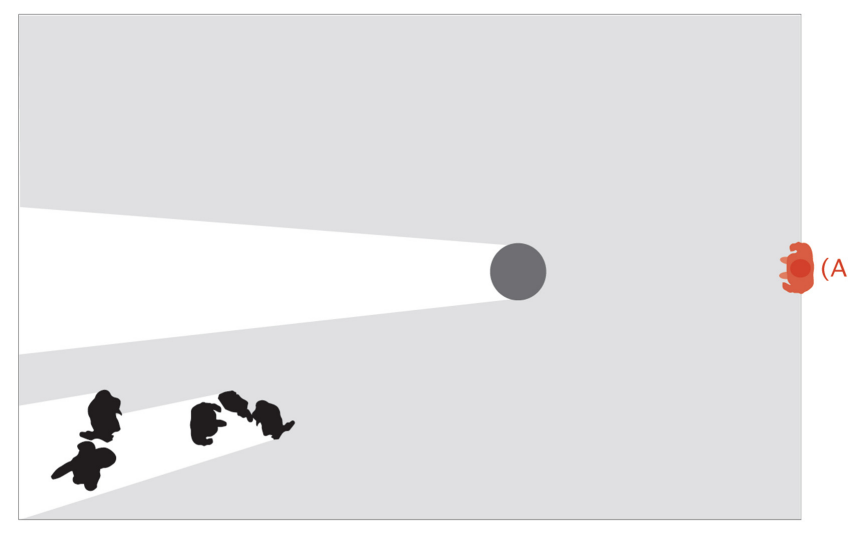

Plan

Fig. 3.1 The logic of a $180^{\circ}$ isovist field from a person's location (A) 
An isovist visualises the geometrical area of a person's panoptical view from a particular location in the built environment. The isovist's area is defined by subjects, objects, and vegetation in the open space under scrutiny. When moving through space, the shape and size of the isovist field changes with every newly occupied location. It is thus possible to visualise visual field sequences of particular movement routes through cities. Figure 3.1 illustrates a $180^{\circ}$ isovist from a person's location in the public realm. The tree close to the person (A) influences their visual field and therefore impacts the isovist field. The same applies to the group of people in close proximity to the tree. Simply speaking, both block the individual's view.

This so-called one-point isovist analysis is mostly useful at a neighbourhood scale. Isovist analysis depicts the degree of visibility of the location of urban artefacts and visualises the visual field area and perimeter. In reverse, in Fig. 3.1 the one-point isovist field also indicates from which locations of the public space the person (A) is visible.

Isovist analysis is useful for testing the impact of new urban interventions and how they will increase or decrease the visual experience from a given location. Inversely, the isovist analysis also allows identifying optimal locations for, for example, a temporary concert stage in a public space. All kinds of obstacles such as vegetation, buildings, and light poles can partly block the view and therefore reduce the isovist field. Nothing is more annoying than staring at a light pole or tall person in front of you at a live concert in an urban square. In general, the applicability of isovist fields is manifold. Figure 3.2 depicts two different isovist fields for the same setting of park X.

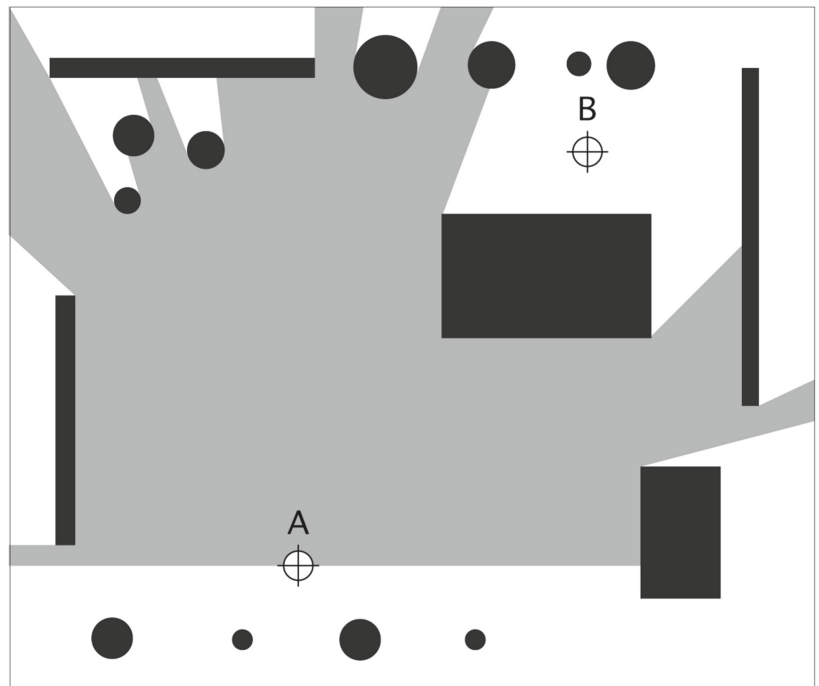

Example of a $180^{\circ}$ isovist

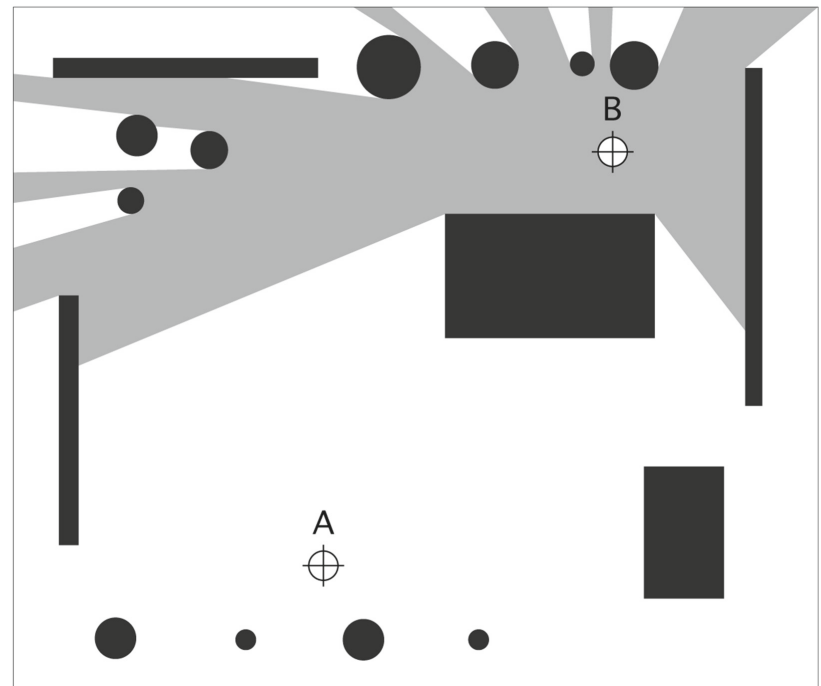

Example of a $360^{\circ}$ isovist

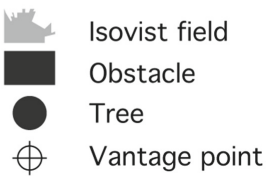

Fig. 3.2 Two different isovist fields from vantage point A applying a $180^{\circ}$ view (image left) and from vantage point B applying a $360^{\circ}$ view (right image) for our example of park $\mathrm{X}$

An isovist visualises the geometrical area of a person's panoptical view from a particular location in the built environment. In Fig. 3.2, the visual field for vantage point A depicts what a person sees when entering the park, whereas the visual field for vantage point $\mathrm{B}$ depicts the view when the person turns around on their own axis. While the $180^{\circ}$ isovist example illustrates an individual overview of a certain space, the $360^{\circ}$ isovist depicts a low viewshed due to the hidden location of vantage point $\mathrm{B}$ behind the building. This hidden location is an example of spaces that are highly likely to be used for criminal activities. The person in location B makes sure that they can hardly be seen by other people in the park. For analysing surveillance of a given space, a $360^{\circ}$ isovist is conducted. In our example, the individuals do not see each other (represented by vantage point $\mathrm{A}$ and $\mathrm{B}$ in Fig. 3.2). 
Figure 3.3 illustrates four sequences of $180^{\circ}$ one-point isovists for space X. None of the indicated four individuals can see each other. Red and yellow as well as green and blue isovist fields overlap. The higher the overlap of isovist fields from different strategic urban locations, the easier people navigate through the space. This is due to the provision of consistent visual information about the space they move through.

Isovist sequences are connected to Gordon Cullen's concept of 'serial vision' (1971). Cullen draws a panoptical view sketch from each strategic location along a chosen route in order to achieve visual coherence and organisation among the jumble of buildings, streets, and spaces that make up the urban environment. In many ways, Cullen's method is dealing with intrinsic properties of space, whereas an isovist analysis is dealing with extrinsic properties of space. Cullen is drawing the surface texture of the objects we see at every vantage point, whereas the isovist analysis is visualising the spaces between the objects.

Fig. 3.3 Sequences of isovists for the ground map (above) and section (below) of an exemplary space X. Horizontal (above) and vertical (below) representations of a $2 \mathrm{D}$ isovist analysis
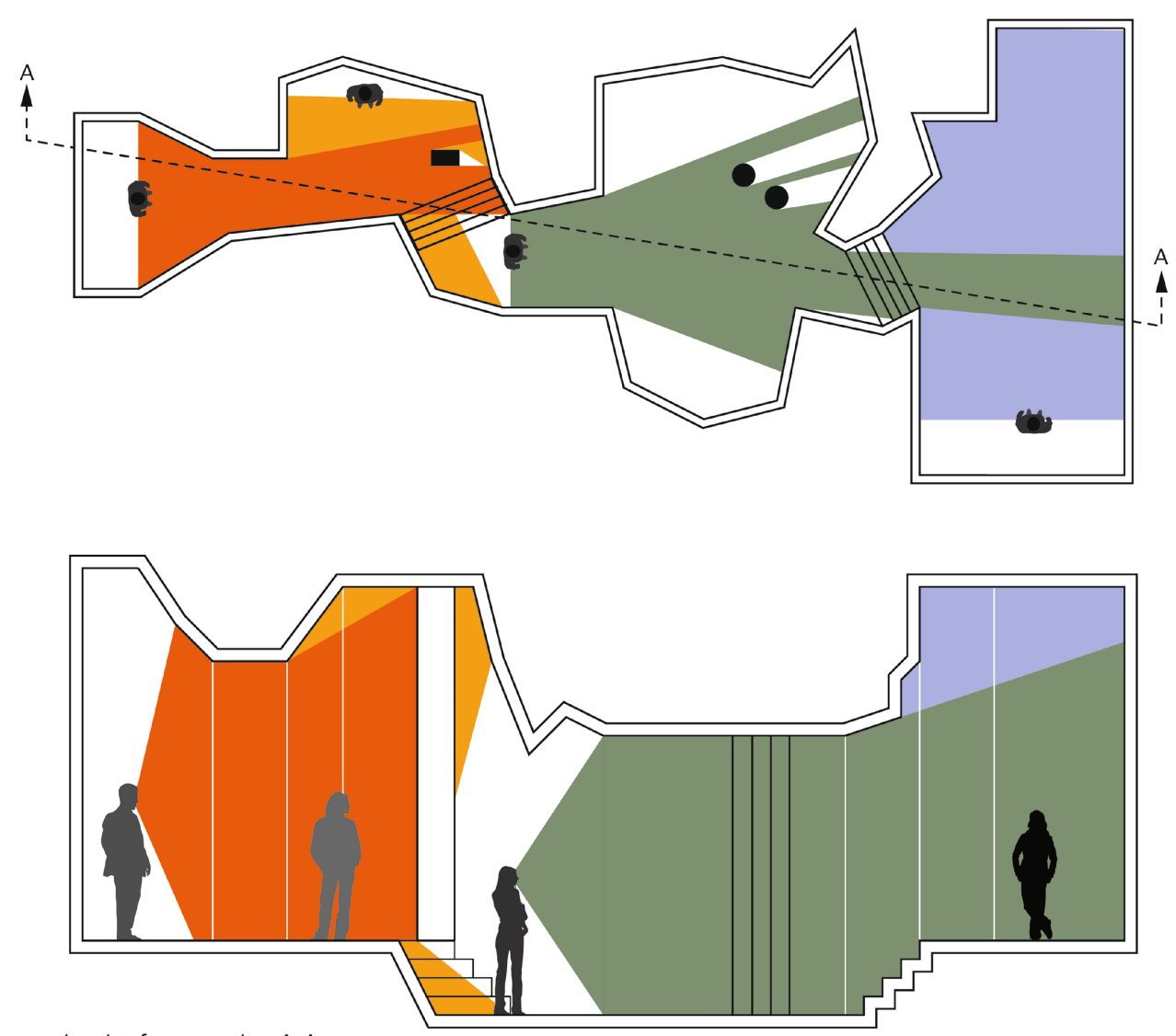

Isovist from section A-A

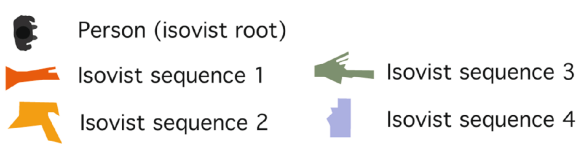


Isovists can be represented in several ways. Figure 3.3 shows a plan and a section of space $\mathrm{X}$ with the viewpoints of four people. In the plan, an isovist of $180^{\circ}$ is used. In section a-a, an isovist of $120^{\circ}$ is used. The persons have to move their eyes a little up and down to cover this view field. The isovists in section A-A can deal with height differences in public spaces. In addition, we applied serial vision to a route through the town centre of Haarlem close to Amsterdam (Fig. 3.4). The route is

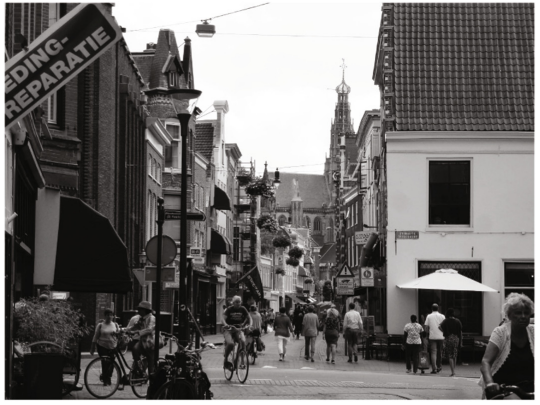

1 -

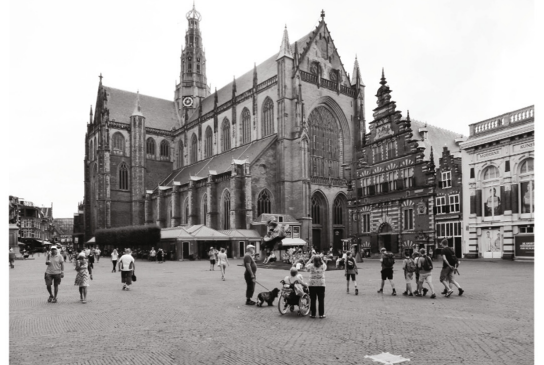

4

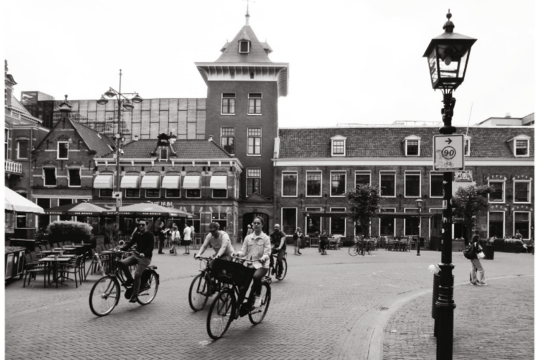

7

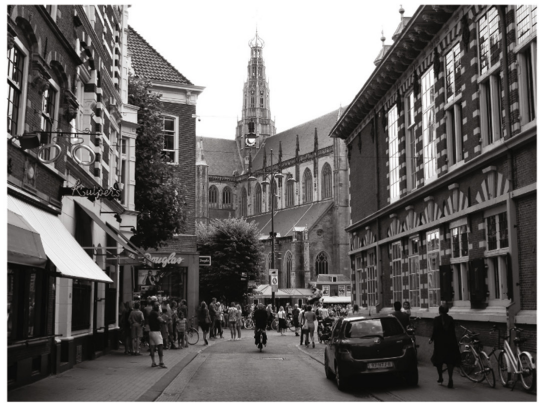

2

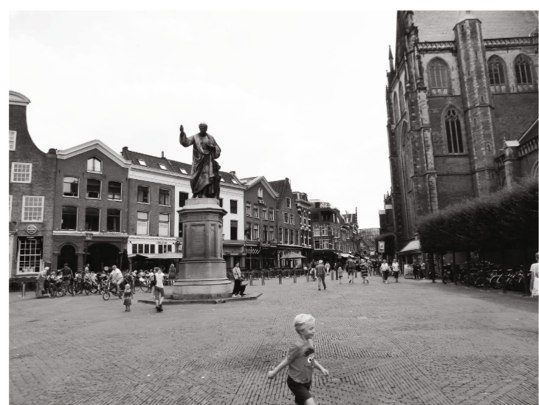

5

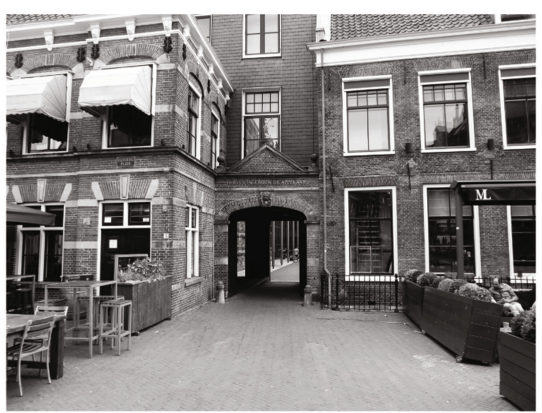

8

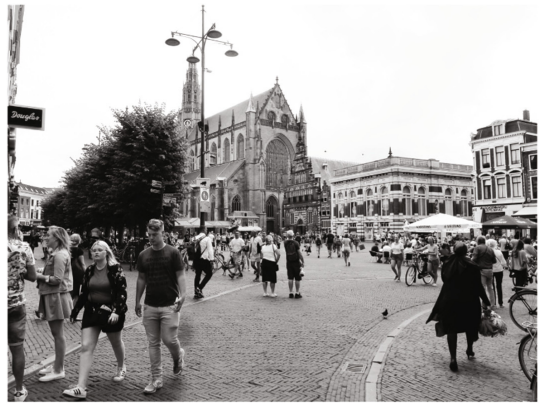

3

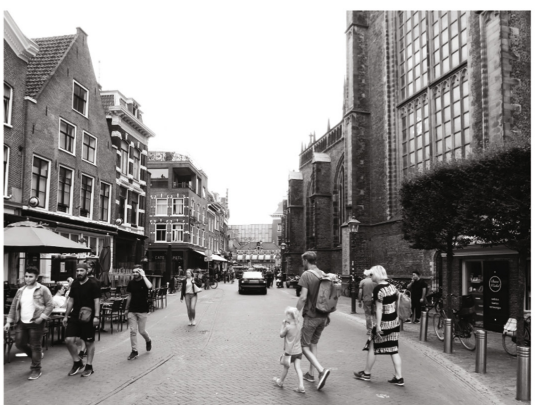

6

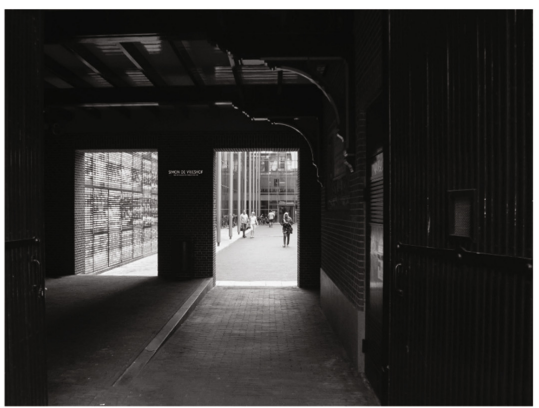

9

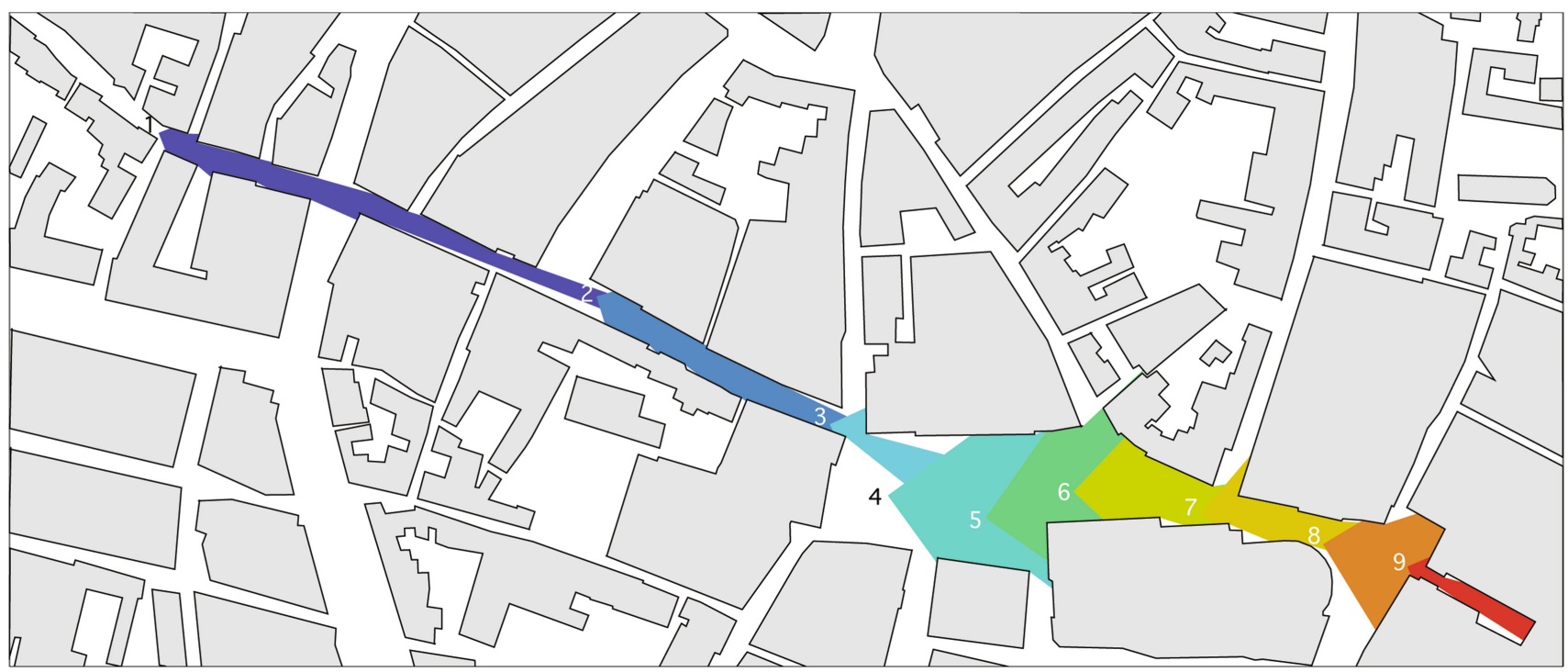

Fig. 3.4 A serial vision from a route in Haarlem applying $90^{\circ}$ isovists 
illustrated with photos taken from the isovists' vantage point of the analysis. Several $90^{\circ}$ isovists were conducted. The photographs numbered 1-9 show how the impressions of the surface of buildings and public spaces can change from point to point. In particular in open spaces, such as the main square, the view field can change a lot after only a couple of meters. Therefore, the one-point and the serial vision route isovists can be useful in urban planning.

Two well-known urban projects for the application of isovist analysis are the redevelopment of Trafalgar Square in 2003 and the Millennium Bridge project in 2000 in London, both by the architect firm Foster+Partners. For both projects, isovist analysis was applied in a descriptive and predictive way. Trafalgar Square was an isolated island for pedestrians with two columns in its centre and surrounded by heavy vehicular traffic. The natural movement paths to enter and exit Trafalgar Square were blocked by fences and signs. An empirical data collection in the form of recording stationary activity and pedestrian movement showed that Londoners avoided the centre of Trafalgar Square and that tourists failed to make the journey between Trafalgar Square and Parliament Square. Some tourists tended to stand on a traffic island in the middle of the most trafficked road for taking pictures. According to the isovist analysis taken from that spot, pedestrians had the largest overview over the square and into the streets leading to the square. One could also see all the way to Buckingham Palace from that isovist root (Space Syntax Laboratory 2001). A set of space syntax analyses was carried out to test and validate urban design options to improve pedestrian accessibility to the centrally located fountains. At present, Trafalgar Square is a central meeting destination for Londoners and tourists alike (Fig. 3.5).

For the Millennium Bridge project, the isovist analysis was applied for proofing the optimal location for the new Millennium Bridge to decision makers. Further, the isovist analysis evidenced the vast visual field the bridge would cover when completed. The visual field included overviews over the Thames River, covering major tourist icons like Big Ben, Westminster Abbey, the Millennium Wheel, St. Paul's Cathedral, Tower of London, and Tower Bridge (Space Syntax Laboratory 1994). All these artefacts are recognised as defining the image and identity of London. Isovist analysis demonstrated how these artefacts are all visible from the location of the Millennium Bridge (Fig. 3.5).
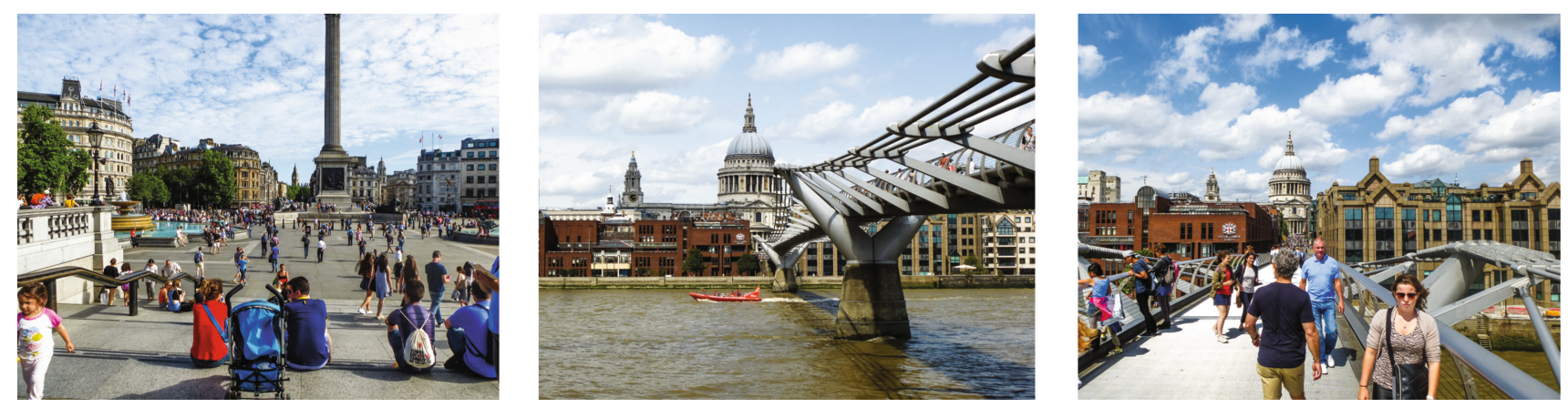

Fig. 3.5 Impressions from Trafalgar Square (left) and the Millennium Bridge (middle and right) from 2015

For conducting an isovist analysis, the root of the visual field can be located at the most-used space to study the kind of overview a person has from it. Conversely, the root of the isovist can also be located at places with lower use to identify their spatial features (Trova et al. 1999). For public spaces, stationary social interaction, for example, where people stand and sit, correlates with the isovist field (Trova et al. 1999). The higher the density of people at a certain location, the larger the overall isovist field as the sum and overlap of all people's individual isovist fields.

Until now, the 2D isovist analysis has been mostly applied in urban research and practice. A 2D isovist analysis provides a quick and robust way to gain an overview of a given spatial situation in a time-efficient manner. However, 3D isovist analysis is at the forefront and can add value when, for example, working with 3D city models in virtual reality. 
The added value of a 3D analysis using 'voxels' as compared to a 2D analysis using 'pixels' is in line with the thoughts of van Bilsen (2009) because it overcomes the following shortcomings: (1) The vertical dimension, e.g. building heights, is ignored in the 2D analysis even though it influences visibility measures, (2) walkable surfaces of cities differ in height such as on hills and bridges, (3) incomplete landmark analysis in 2D analysis if any, (4) a typology based on the full 3D environment is missing, and (5) a connection to cognitive pattern recognition which occurs in $3 \mathrm{D}$ analysis is missing.

In the development of 3D measures for visibility analysis, Fisher-Gerwitzmann and Wagner (2003) developed a tool that emerged from the concept of spatial openness. Following from this, Teller advocated sky-opening maps (2003), Bilsen and Stolk (2007) developed a framework for a 3D isovist-based visibility analysis, Morello and Ratti introduced an urban array of urban-visibility measures called the 'isovist matrix' (2009), Dalton et al. (2015) used information and data from a 3D scan to produce a 3D isovist for the built environment, and Kim et al. (2019) developed a 3D space syntax metric based on 3D isovist capture.

In this context, Dalton et al. (2015) compared the number of times people reported seeing specific content and the places this was displayed in a real built environment with a 3D spatial analysis model of a university campus. The registrations were correlated with the number of isovist values from a $3 \mathrm{D}$ scan. The results from the $3 \mathrm{D}$ visual graph analysis were compared to the $2 \mathrm{D}$ visual graph analysis. The values from the $3 \mathrm{D}$ isovist did not deviate much from the values of the $2 \mathrm{D}$ visual graph analysis. Departing from this insight in the following, we will explore 2D visual graph analysis (VGA) (Fig. 3.6).

Fig. 3.6 The principle of the construction of a 3D isovist (original Dalton et al. 2015; image redrawn)

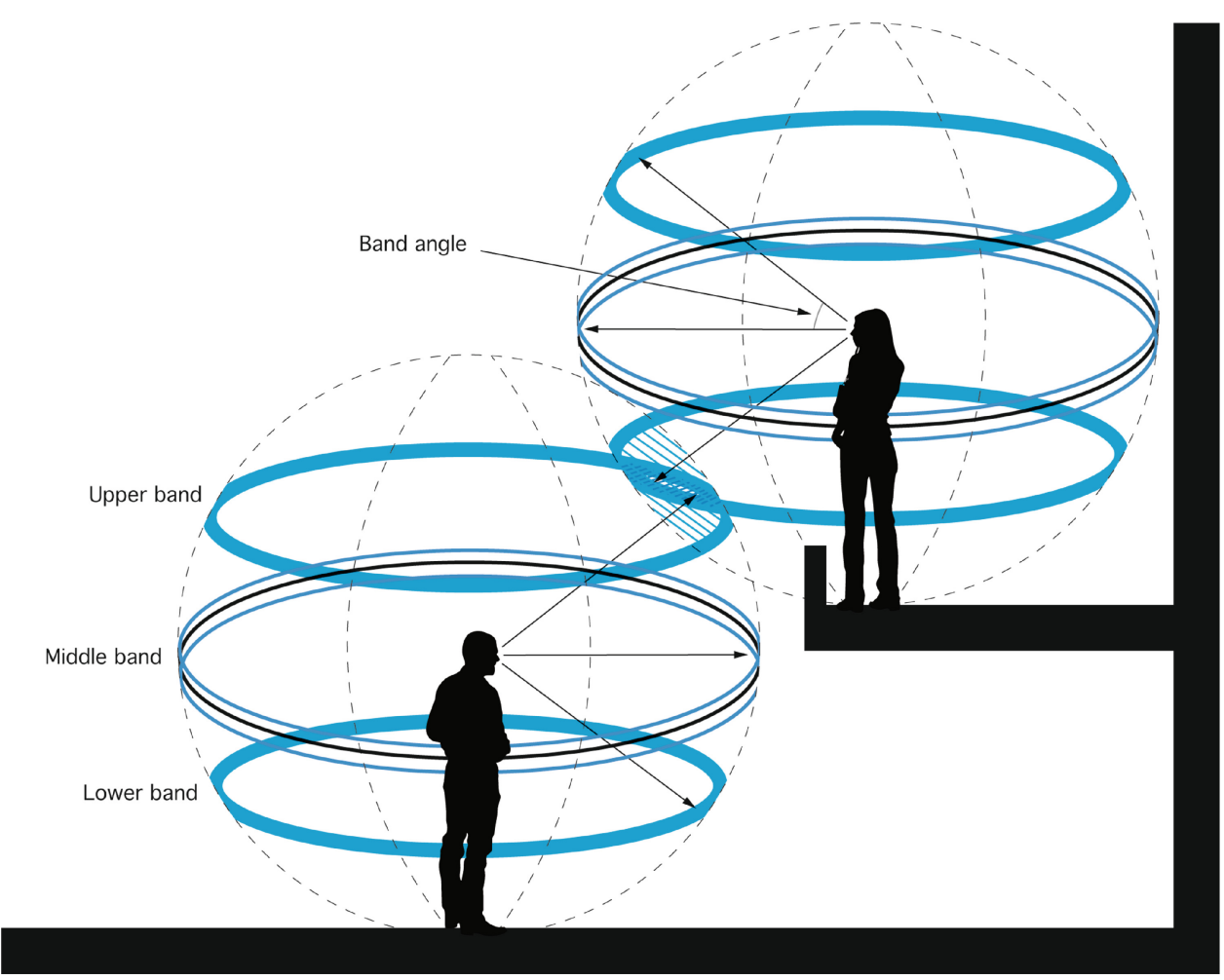




\subsection{Visual Graph Analysis}

Building upon the logic of an isovist analysis, visual graph analysis (VGA) integrates all of the isovist fields from all location points (roots) of a given space. In other words, VGA is a method for analysing the intervisibility connections of urban space. VGA is a raster-based method. For each cell in the grid an isovist is carried out, and its topological visibility in relation to all other cells is calculated. This is done for all cells, and the analysis takes into consideration a cell's centroid as the root. Every move from one cell to another cell in the grid is a topological step, and thus it is possible to calculate how integrated each cell is in relation to all other cells in the grid. Hence, the integration calculations explained in previous chapters can be applied. The VGA calculates how each cell relates to all other cells in the grid. Obstacles like walls, fences, trees, etc. contribute to the topological depth between various cells (Turner 2007).

Prior to the millennium, convex maps were drawn manually, but VGA has replaced convex space analysis. The rule of thumb is to subdivide a space into the least number of convex spaces. Hillier and Hanson (1984, p. 98) define a convex space as "one space where all points within this space are visible to one another". In Fig. 3.7 we illustrate this principle.

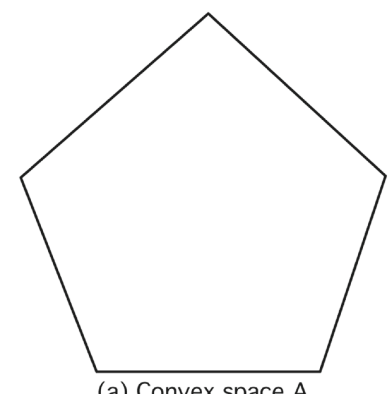

(a) Convex space $\mathrm{A}$

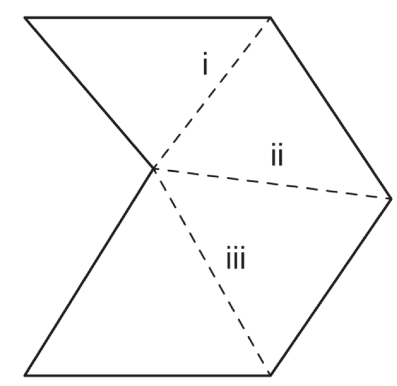

(b) Convex space $\mathrm{B}$

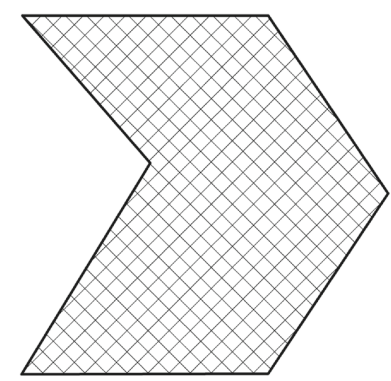

(c) Convex space $\mathrm{C}$

Fig. 3.7 Different types of basic spatial units for the 2D analysis: (a) an entire convex space with no subdivision, (b) a space with three options of subdivision for generating two convex spaces, and (c) a space with a superimposed grid

In Fig. 3.7, the scheme of space A is one convex space, whereas the scheme of space B is two convex spaces. Space B has three options for subdivision, represented by dashed lines (i, ii, and iii). All options are correct. When generating a convex map for a whole neighbourhood, the result is not free from the individual judgement of the modeller. The result can vary slightly when applying a spatial integration analysis to a manually generated convex map, and this particularly accounts for neighbourhoods with organic-shaped boundaries. Space $\mathrm{C}$ is superimposed with a raster, and for space $\mathrm{C}$ it is possible to calculate objectively how each cell in the raster relates to all other cells in the raster. This is the basis for the VGA. 


$$
\begin{array}{lll}
M D_{c}=T D / k-1 & M D_{c} \ldots & \text { Mean depth for each cell } \\
k \ldots & \text { Number of spaces in a system } \\
T D \ldots & \text { Total depth: the sum of all steps from a chosen cell to all other cells in the system }
\end{array}
$$

\begin{tabular}{|l|l|l|l|l|l|l|l|}
\hline 3 & 3 & 3 & 3 & 3 & 3 & 4 & 5 \\
\hline 2 & 2 & 2 & 2 & 2 & 3 & 4 & 5 \\
\hline 2 & 1 & 1 & 1 & 2 & 3 & 4 & 5 \\
\hline 2 & 1 & 0 & 1 & 2 & 3 & 4 & 5 \\
\hline 2 & 1 & 1 & 1 & 2 & 3 & 4 & 5 \\
\hline 2 & 2 & 2 & 2 & 2 & 3 & 4 & 5 \\
\hline
\end{tabular}

(a)

$$
\begin{aligned}
& 5 \times 6=30 \\
& 4 \times 6=24 \\
& 3 \times 11=33 \\
& 2 \times 15=30 \\
& 1 \times 8=8 \\
& 0 \times 1=0
\end{aligned}
$$

Total depth $=125$

MD of orange cell $=125 / 48-1=2.660$

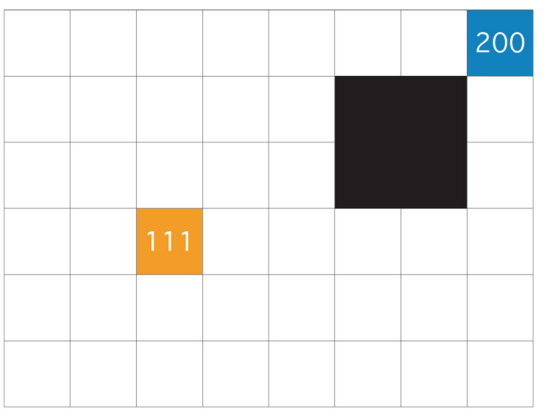

(d) $\mathrm{MD}$ of orange cell $=111 / 44-1=2.581$ MD of blue cell $=200 / 44-1=4.651$

\begin{tabular}{|l|l|l|l|l|l|l|l|}
\hline 7 & 6 & 5 & 4 & 3 & 2 & 1 & 0 \\
\hline 7 & 6 & 5 & 4 & 3 & 2 & 1 & 1 \\
\hline 7 & 6 & 5 & 4 & 3 & 2 & 2 & 2 \\
\hline 7 & 6 & 5 & 4 & 3 & 3 & 3 & 3 \\
\hline 7 & 6 & 5 & 4 & 4 & 4 & 4 & 4 \\
\hline 7 & 6 & 5 & 5 & 5 & 5 & 5 & 5 \\
\hline
\end{tabular}

(b)

$$
\begin{aligned}
& 7 \times 13=91 \\
& 6 \times 12=72 \\
& 5 \times 11=55 \\
& 4 \times 9=36 \\
& 3 \times 7=21 \\
& 2 \times 5=10 \\
& 1 \times 3=3 \\
& 0 \times 1=0
\end{aligned}
$$

Total depth $=288$

MD of orange cell $=288 / 48-1=6.128$

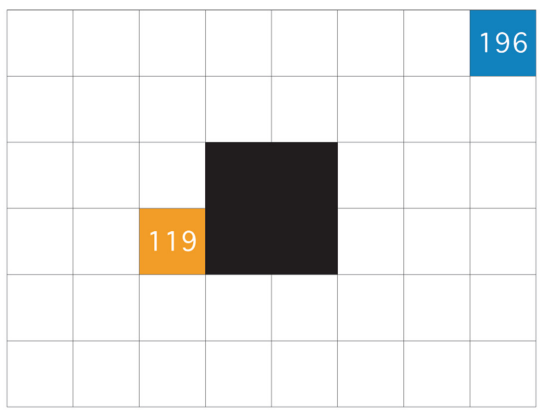

(e) MD of orange cell $=119 / 44-1=2.767$ MD of blue cell $=196 / 44-1=4.558$

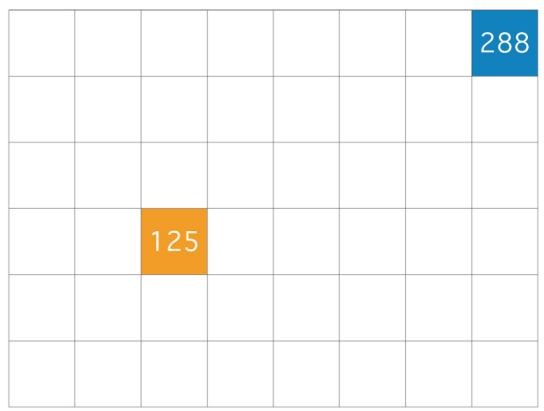

(c) MD of orange cell $=125 / 48-1=2.660$ MD of blue cell $=288 / 48-1=6.128$

Fig. 3.8 Point-depth analysis: calculating the mean depth (MD) for two different roots excluding and including an obstacle with different positions in the grid 
For drawing the digital base map for conducting all kinds of 2D spatial analyses, the following needs to be done. First, all obstacles such as buildings, fences, statues, and ponds need to be drawn as closed polygons on the map. Second, the chosen study area cannot be too big. A rule of thumb for the area's boundary is to include 2-4 blocks around the areas of interest. In most cases, the 2D spatial analyses tools are used for analysing all kinds of public squares. Finally, the study area needs to have a drawn boundary. This boundary is also a closed polygon, and it either follows the logic of the streets as a frame like in our example for Haarlem (Fig. 3.4) or it follows the street plinth of the study area. The more fine-grained the raster for the analysis, the more accurate the VGA results. Overall, VGA indicates how easy or difficult it is to orientate and navigate through neighbourhoods. Moreover, VGA indicates location potentials for stationary activities including social interaction in public squares and streets. Thus VGA is a static local measure.

The same logic for calculating the integration for axial maps also applies for VGA. The mean depth is calculated by the total depth divided by the number of cells minus one. For each step from one cell to another cell in all directions, a syntactic step is taken.

Figure 3.8 illustrates the principle on how to calculate the mean depth (MD) for a raster with two examples of different root cells (nodes). The same mathematical formula for calculating topological distance used in Chap. 2 is used. In example (a), the root indicated in yellow shows how this cell is connected to all others. Example (b) follows the same principle with a different root indicated in blue. The root in example (a) is located more centrally in the system than in example (b). Therefore, the system in example (a) appears shallower with a lower mean depth value than example (b).

The blue root in Fig. 3.8 is located at the upper edge of the system and therefore is not as well connected to all other cells in the system compared to the yellow root. Following this, for example (b) the mean depth value is higher and the system is deeper from this specific location than the yellow cell. The conclusion is that in example (a), all cells in the system are easier to reach compared to example (b) from the given root cell.

If we place an obstacle in the raster, the calculation takes it into consideration. In our examples (d, e, and f), our obstacle covers four cells in three different locations. Again, we apply to all examples both roots, marked in yellow and blue. All three examples highlight how the position of the obstacle influences the mean depth value.

Following a similar principle, the so-called 'through vision' can be calculated. Through vision analysis depicts the degree of through visions for a neighbourhood or public space. A through vision is the longest possible continuous view. All spaces or cells that can be seen from one point get the same value, like 1 . This is the first step. When turning around a corner, all the spaces that can be seen get a new but same value. This is the second step.

Figure 3.9 shows how a through vision is calculated by applying the same setting for the raster, root cells, and obstacles as for calculating the mean depth for the VGA in Fig. 3.8. The red colour shows where the cell is located and is step 0. The yellow colour shows all the spaces that can be seen from the red root cell, thus step 1. The green cells show all the spaces that can be seen when 'turning around the corner' of the black obstacle. This is step 2. When turning yet another corner, the blue coloured cells are step 3 .

The mean depth values of the through vision analysis vary according to the location of the obstacle in the grid. The closer the obstacle is to the root cell, the higher the through vision's mean depth value and vice versa. Seemingly, an object located in the middle of an urban space segregates the view field more than when it is placed on the edge. Therefore, through vision analysis from every point in a given urban space can show the degree of visibility for long distances. While the point-depth analysis shows the degree of adjacency, the through vision analysis shows the degree of through-visibility. 
Fig. 3.9 Through vision analysis: calculating the mean depth (MD) for two different root cells excluding and including an obstacle with different positions in the grid
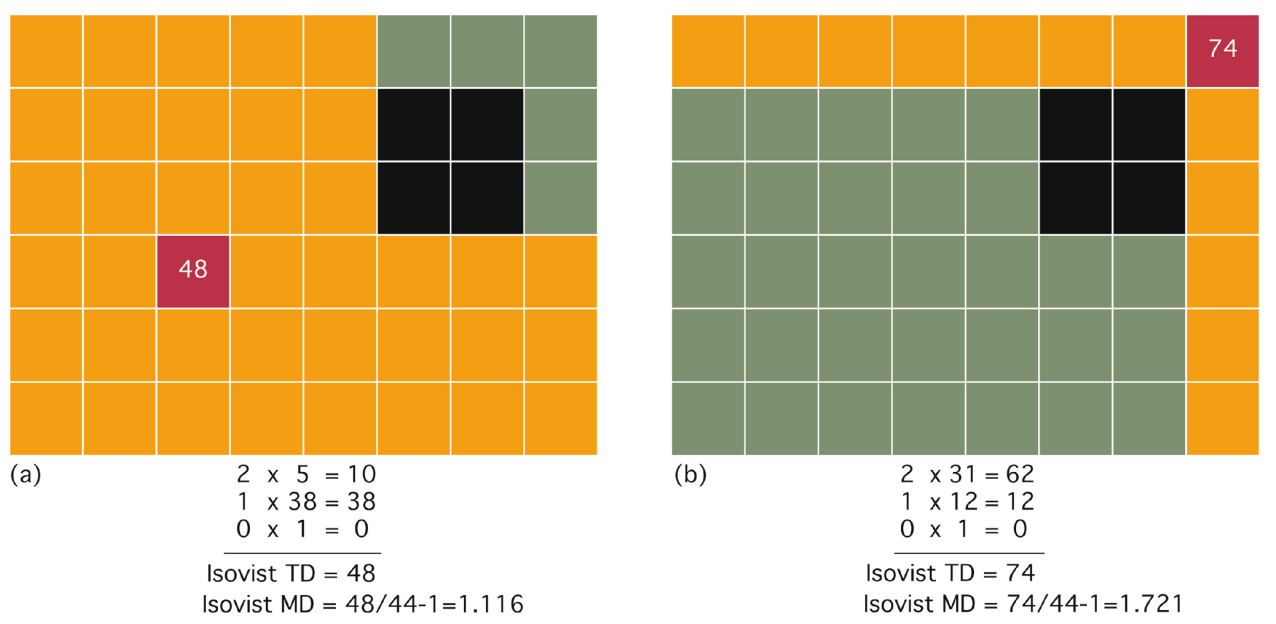

(b)

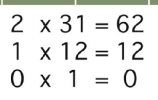

$\frac{0 \times 1=0}{\text { ovist TD }=74}$

Isovist TD $=74$
Isovist MD $=74 / 44-1=1.721$

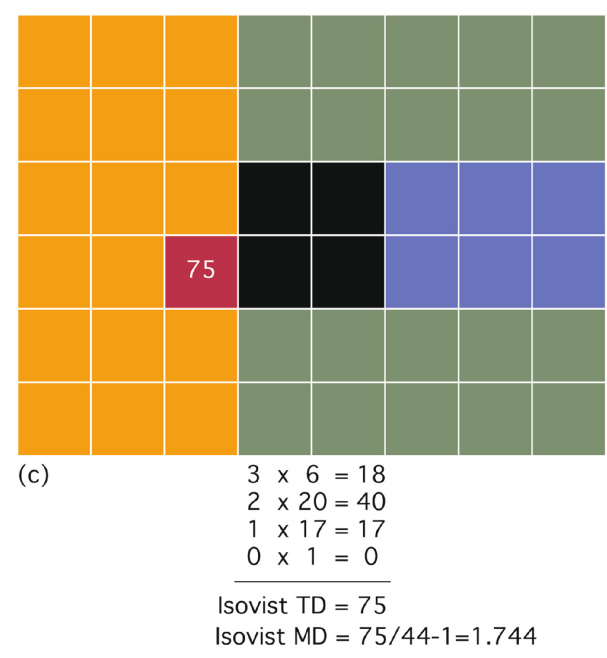

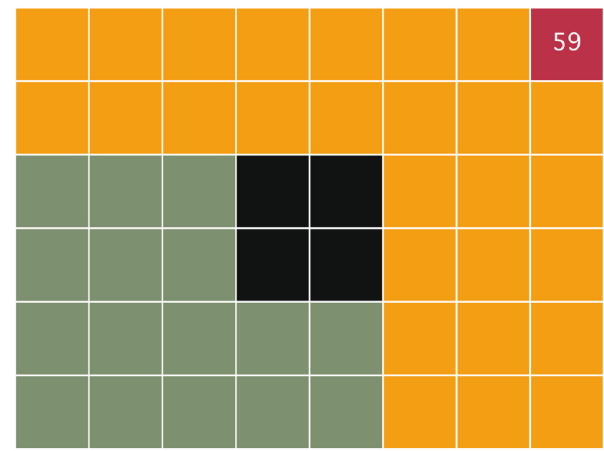

(d)

Often, important artefacts are placed at the end of the sightline of a through vision. Examples are The Spanish Steps in Rome at the Piazza di Spagna, the Siq in Petra in Jordan, and London Town Hall next to Tower Bridge in London, as shown in Fig. 3.10. Conversely, large open spaces in cities tend to have high values on both the VGA and through vision analysis. Figure 3.11 shows the Old Town Square in Prague and one of the main squares of the Forbidden City in Beijing. 

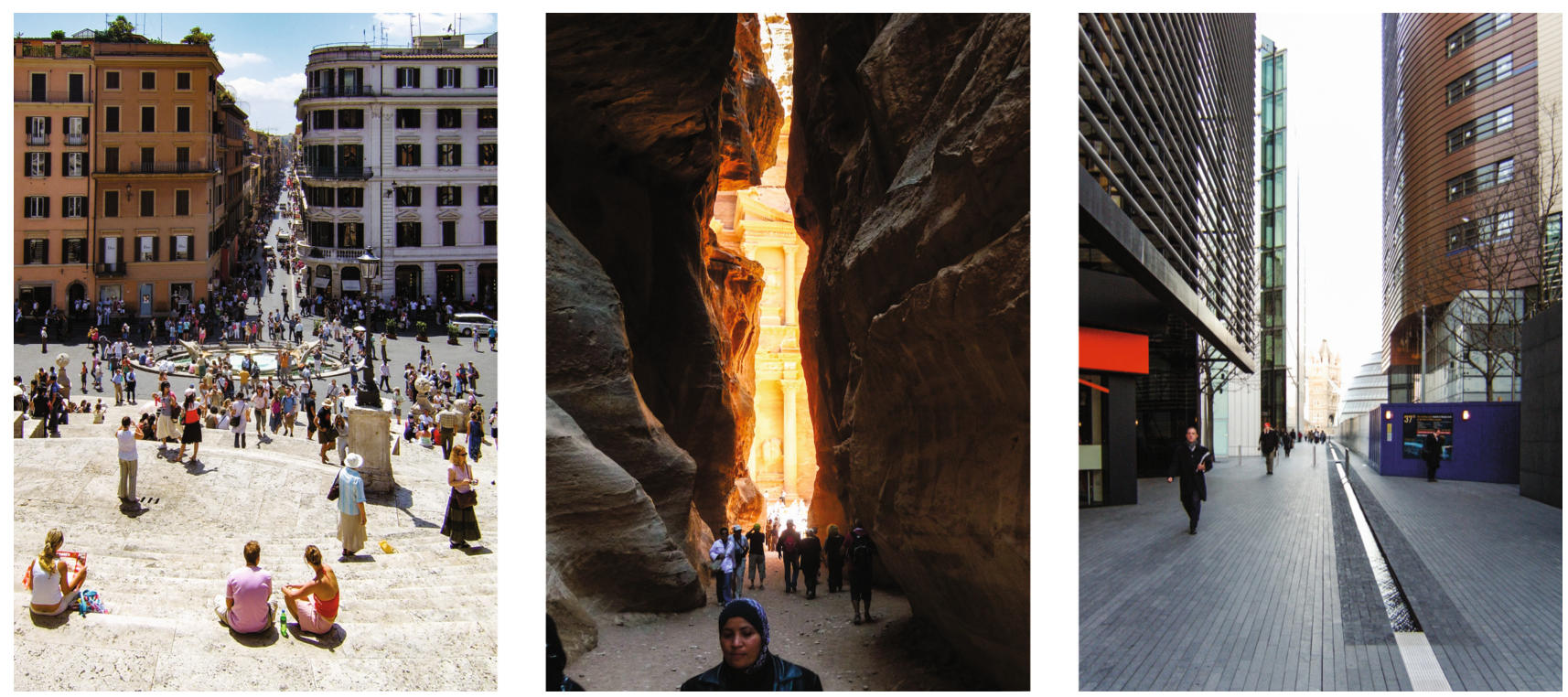

Fig. 3.10 Examples of public spaces with a high degree of through vision: (left) The Spanish Steps in Rome, Italy, (middle) the Siq in Petra, Jordan, and (right) London Town Hall in London, UK
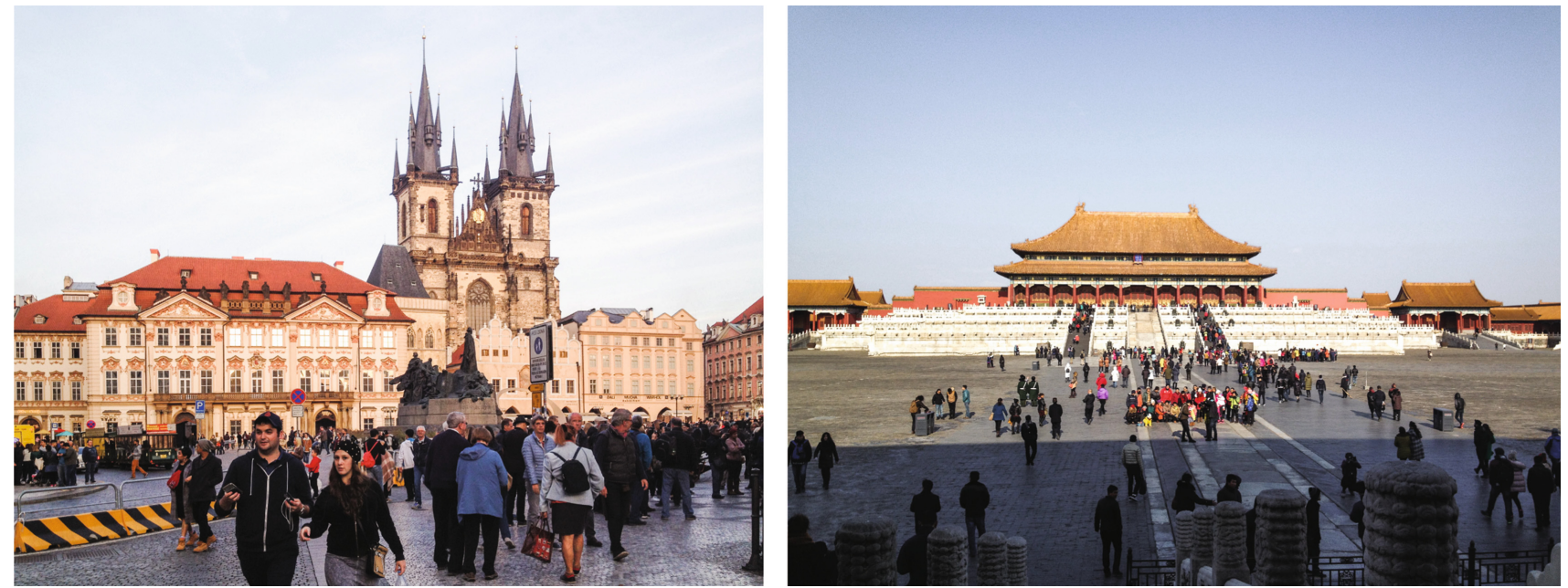

Fig. 3.11 Examples of public spaces with a high degree of visibility (VGA): (left) The Old Town Square in Prague and (right) the Forbidden City in Beijing 
For park X, we conducted both a VGA and a through vision analysis (Fig. 3.12). For public spaces such as parks or squares, high intervisibility and a high degree of through vision often overlap. This indicates that those locations are the 'hot spots' for orientation and navigation. In the analysis, the red areas indicated locations in park X that both analyses found to be the most integrated spaces, whereas the areas in blue indicated the most segregated spaces located behind the trees, fences, and buildings. For the point-depth analysis, a syntactic step was taken from one cell to the next cell. For the through vision analysis, the large visible surfaces as a whole were taken as one syntactic step. This analysis further indicated movement routes to or from the park and between and behind trees, fences, and buildings.

Fig. 3.12 Point-depth analysis (a) and through vision analysis (b) for park $\mathrm{X}$

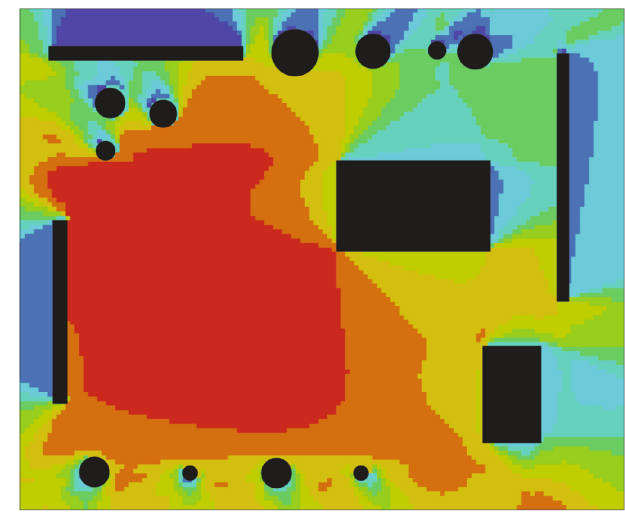

(a) Point depth analysis

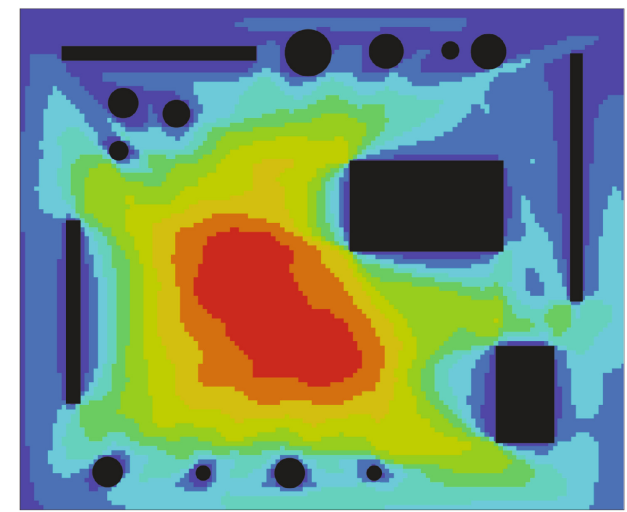

(b) Through vision analysis
Integration/
Strategic visibility righ - low

In Fig. 3.13, we applied the point-depth and through vision analyses to the areas around the Old Town Square of Prague. The point-depth analysis in image (a) shows that the square is the most visible space in the neighbourhood. In contrast, the through-vision analysis illustrates the longest total through vision, which is influenced by the morphology and shapes of the urban blocks. This has an effect on the integration calculation of the through vision. Often, the largest flow of people can be identified in the most integrated spaces when entering the square. Interesting enough, adjacent to the most integrated spot the statue of Johannes Hus is located. For the VGA (c) and through vision analysis (d), the statue of Johannes Hus was added to the model as an obstacle. For users of the square, it seems that the statue is located very centrally in the square. However, the statue's slightly off-centre position does not affect the high degree of through vision and visibility. 

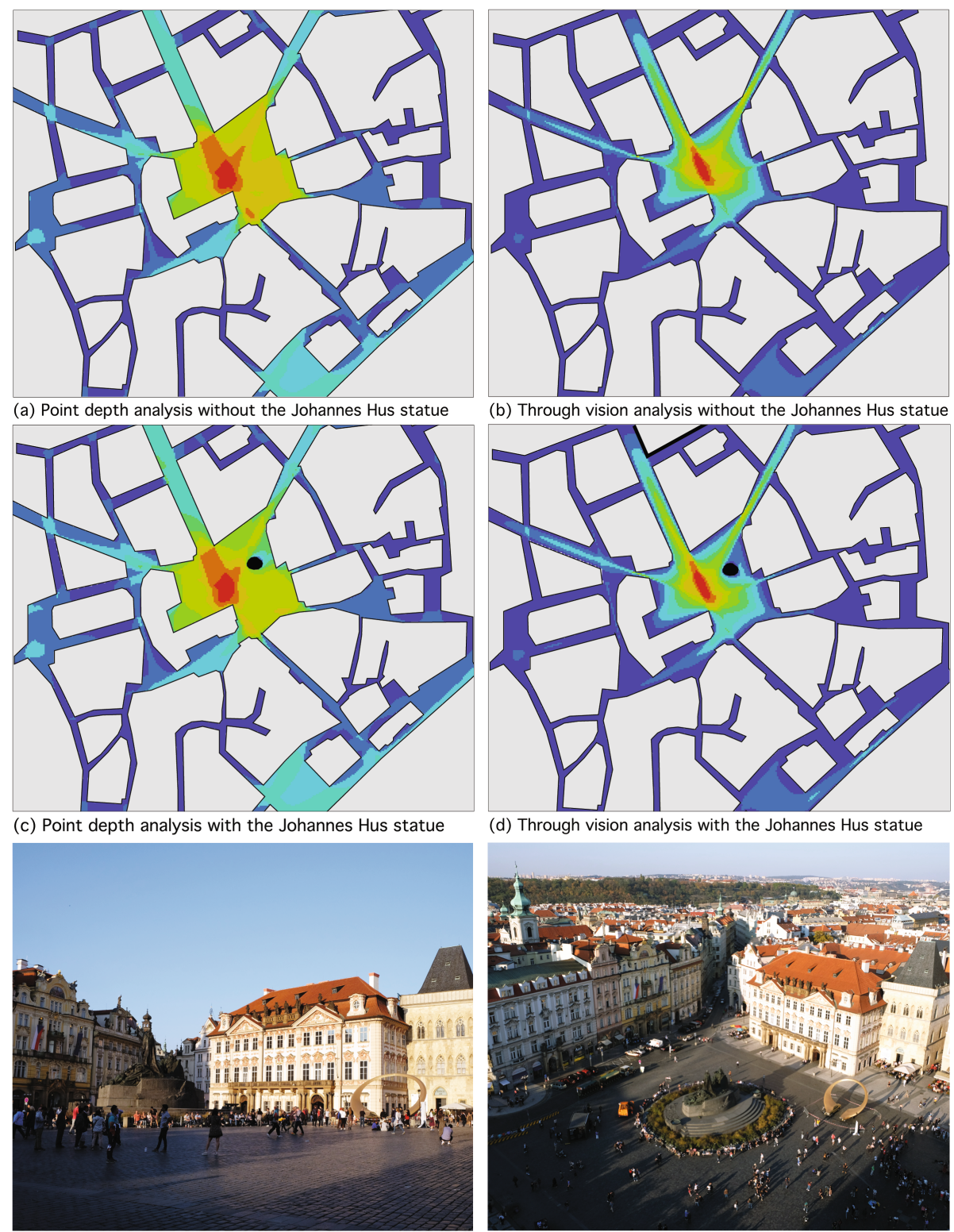

(d) Through vision analysis with the Johannes Hus statue

(e) Prague: The old town square seen at eye level

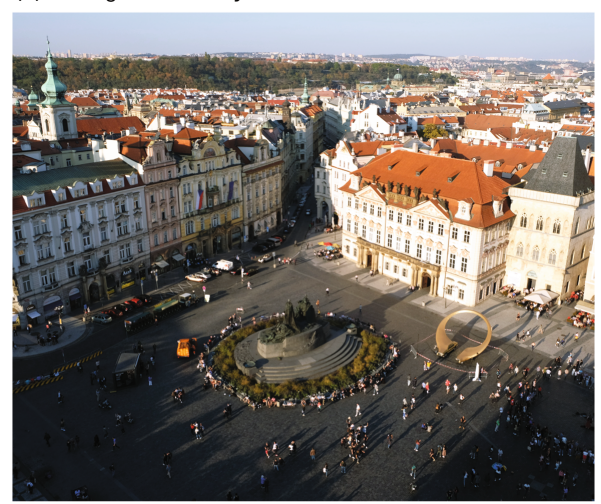

(f) Prague: The old town square seen from above

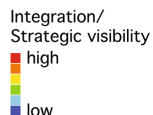

Fig. 3.13 Point-depth analysis (a and $\mathbf{c})$ and through vision analysis (b and $\mathbf{d})$ for the Old Town Square in Prague. Both photos (e and $\mathbf{f})$ show the square with the Johannes Hus statue

VGA can be applied to demonstrate the visibility of strategic entry points into a public square and the optimal locations for monuments, fountains, or temporary structures in a public square (Yamu et al. 2021). At the architectural scale, VGA is useful for defining the locations of exits and fire staircases in public buildings or the anchor stores in shopping malls based on their visual façade exposure. VGA depicts how new urban interventions increase or decrease existing views. Moreover, VGA can be used in landscape architecture to evaluate the design of outdoor areas and parks and gardens. VGA allows one to identify 'hidden corners', which are places attractive for criminal activities. This analysis links to Bill Hillier and Simon Shu's concepts of natural surveillance (2000) and Jane Jacob's 'eyes on the streets' (1960) for generating safe urban areas. 
When studying modernist neighbourhoods in the Zeitgeist of Mies van der Rohe or Le Corbusier, large portions of plots remain unbuilt. In historic urban areas, we find a clear distinction between the public and the private space. For modernist neighbourhoods, the semi-public or semi-private space between the public street and the private housing space softens these clear boundaries. Thus, in these areas streets are defined by 'weak boundaries' compared to historic neighbourhoods with their 'hard boundaries'. The weak boundaries are defined by the border of the grass field, trees, planting, fences, pavements, and sidewalks (Trova et al. 1999). Due to the weak boundaries, the field of vision is enlarged, which dilutes and therefore minimises the wayfinding in the street. Modernistic neighbourhoods are often not very inviting and attract criminal activities due to their imbalance between high-rise buildings and open space. The geometry of the field of vision and intervisibility as well as through vision plays a role in orientation, wayfinding, and people's behaviour (Fig. 3.14).

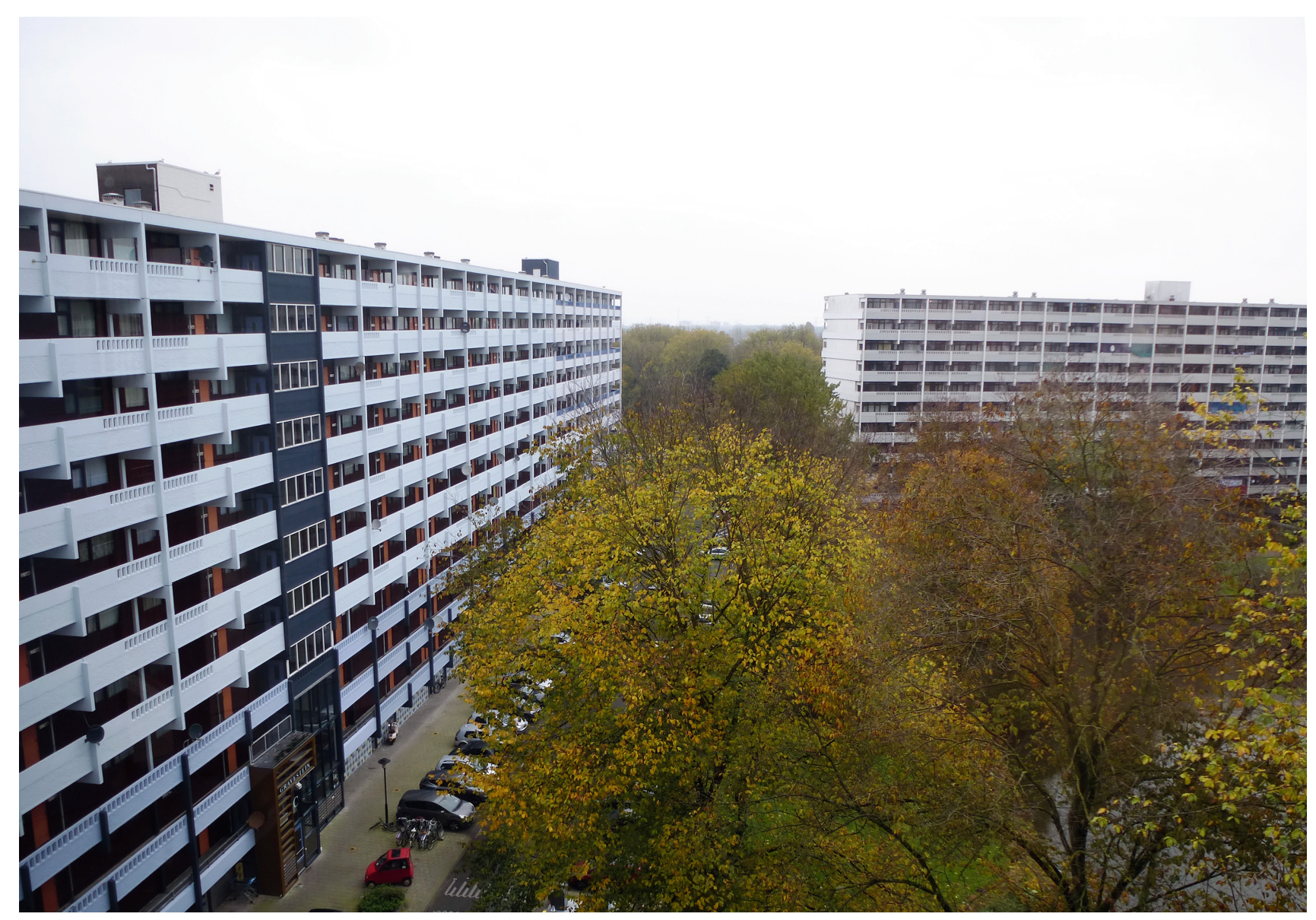

Fig. 3.14 Photo of the modernist neighbourhood Bijlmermeer in Amsterdam with its weak boundaries

For testing several locations for certain artefacts in order to identify their optimal locations, a one-point isovist step depth analysis can be carried out. This allows one to understand how the visibility changes within the vicinity using the different options. The degree of visibility can vary depending on the location of the isovist root. Our example illustrates the degree of visibility from points A, B, C, and D for park X (Fig. 3.15). The green colour shows the one-step isovists for all four locations, which show what can be directly seen from the isovist root. Location B has the lowest degree of visibility, whereas locations $\mathrm{C}$ and $\mathrm{D}$ have the highest degree of visibility. When placing, for example, a statue or a fountain, vantage points $\mathrm{C}$ and D have the largest isovist surface for park X. 
Fig. 3.15 A one-point isovist step depth analysis from four different locations in park $\mathrm{X}$
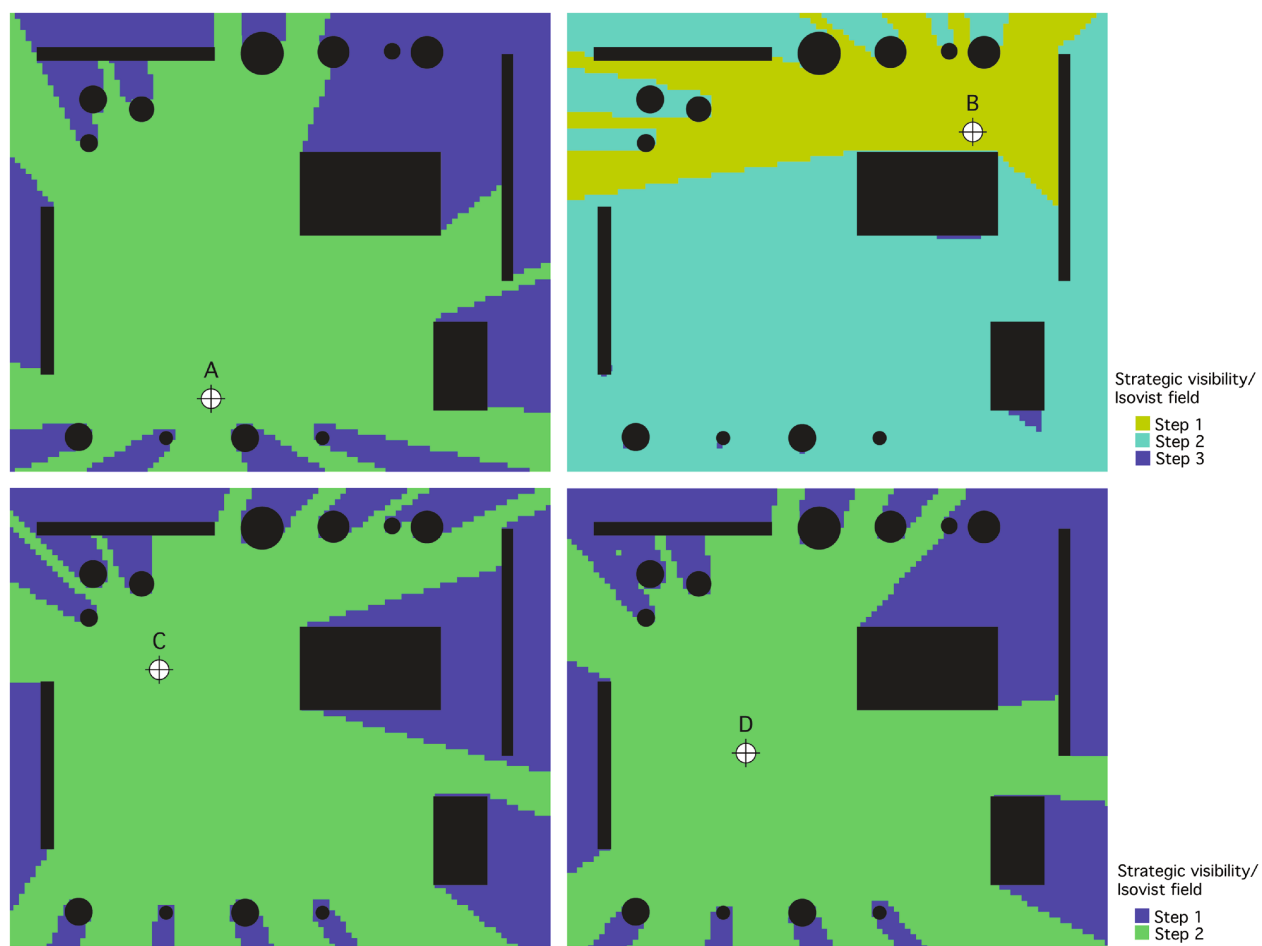

Moreover, it is also possible to test one-point step depth analyses of isovists at several points at the same time. Figure 3.16 shows an example of the historic core of Sophia from the eighteenth century, which no longer exists. The base map was drawn using historic maps.

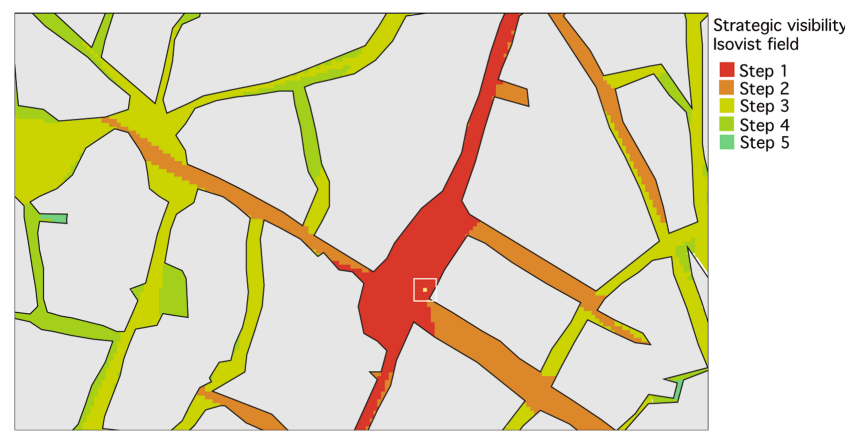

(a) One-point step depth analysis

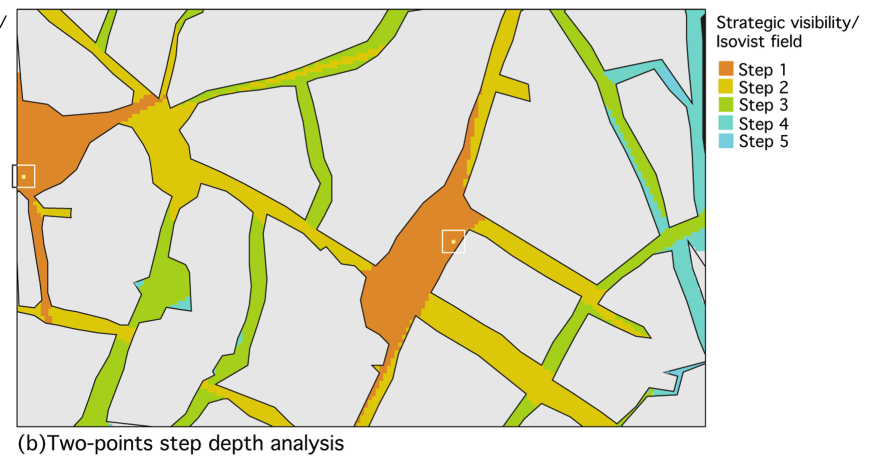

(b)Two-points step depth analysis

Fig. 3.16 Point-step depth analysis from one point (a) and two points (b) from an ancient area from 1300 in the centre of Sofia, Bulgaria

Culagovski et al. (2014) developed the first 3D VGA tool by changing from the 2D grid to a rectangular digital-elevation model where a 3D input model was represented as a grid of squares with associated elevations. For each square of the grid, a sightline analysis was performed with every other grid square. By treating each square as a node and each sightline as an 
edge between two nodes, a 3D visibility graph was constructed. For their study, the following four measures of configurational properties from graph theory were applied:

(1) closeness centrality or integration (Hillier and Hanson 1984),

(2) betweenness centrality as a measurement of control because the nodes with higher values are important communication routes within the graph,

(3) degree centrality representing the area that is visible from a given point as a local measure, and

(4) clustering coefficient (Watts and Strogatz 1998) representing the number of connections between the nodes of a given node's neighbourhood divided by the possible connections within the neighbourhood.

However, for this first approach, it is very time-consuming to build the 3D base map and process the model. Conversely, currently the $2 \mathrm{D}$ VGA is a robust analysis that has proven that the obtained results correlate with people's real-life social behaviour. Furthermore, the 2D VGA is a time-efficient analysis in comparison with the 3D VGA.

\subsection{All-Line Axial Analysis}

An all-line axial map represents all possible sightlines in all accessible spaces in a built environment. While VGA depicts how integrated a visibility point in a spatial system is in relation to all other visibility points of a spatial system, the all-line axial analysis shows how integrated each sightline is in relation to all other sightlines of a spatial system. Hillier (1996) and Turner (2005) define the all-line axial map as "a set of lines made up of all lines drawn tangent to vertices that can see each other".

The all-line axial map is generated from publicly accessible spaces represented as one spatial entity taking into consideration spatial obstacles. When weak boundaries between public and private spaces exist in a neighbourhood such as for modernist neighbourhoods, the all-line axial map can be advantageous for a local scale. For this situation, it is in general difficult to draw an axial map representing the fewest sightlines, but this allows one to grasp all of the open spaces between freestanding objects. The all-line map, including integration values for each sightline, can be generated using the space syntax computer application 'DepthmapX'. This is a simple and fast procedure. Reversely, it is also possible to generate an axial map from the all-line axial map. This is often favoured by archaeologists for the analysis of excavated towns.

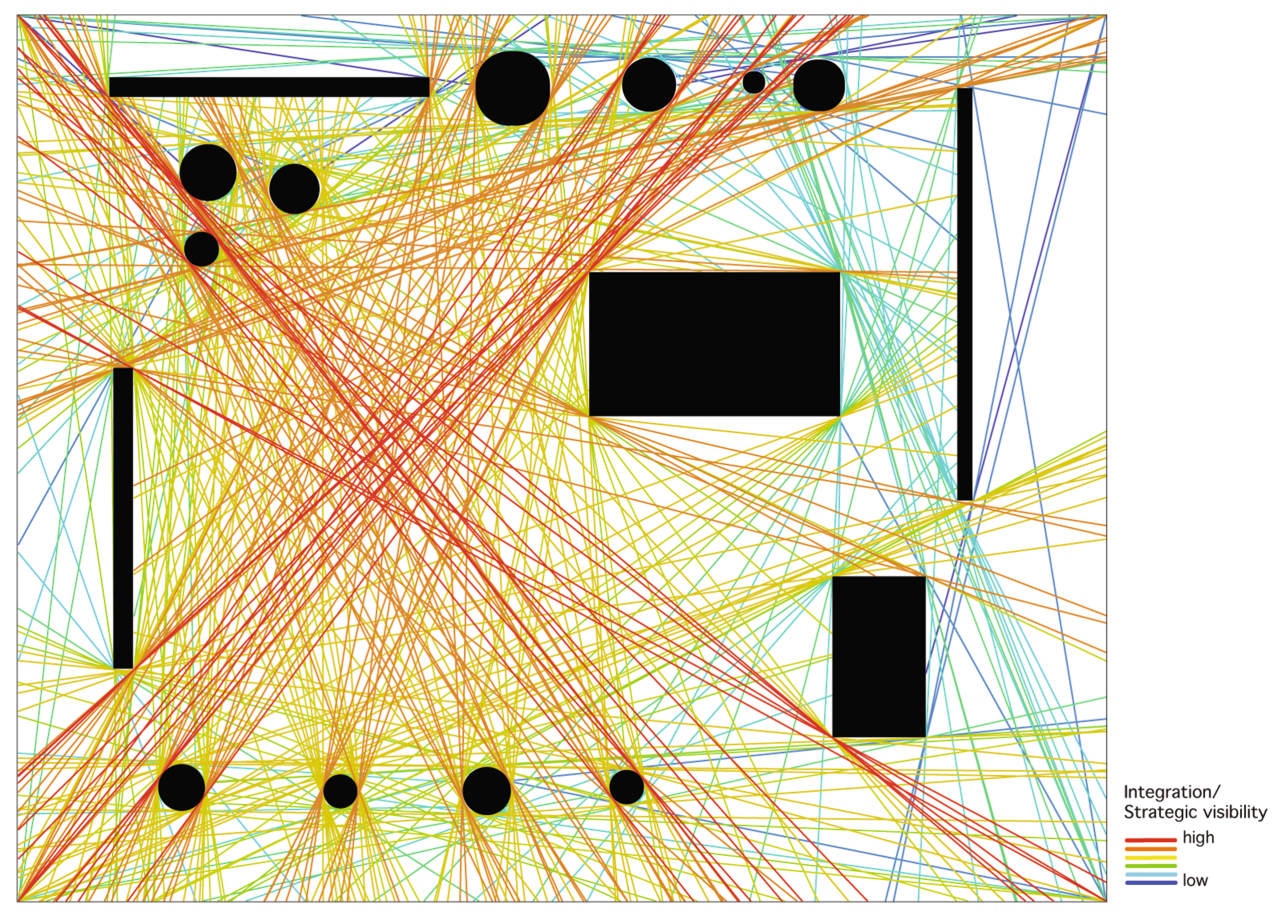

Fig. 3.17 All-line axial analysis for park X 
The all-line axial analysis for park $\mathrm{X}$ shows that areas behind buildings and walls have low intervisibility values. The large open area in the park's centre is the most intervisible and integrated area of the park (Fig. 3.17). Red sightlines are the most integrated axial lines, and blue sightlines are the most segregated. The all-line axial analysis demonstrates the degree of integration of all possible sightlines in an urban area, and it is useful in areas with spaces and boundaries defined by a street network. The same mathematical formula for calculating axial integration is used in the all-line analysis.

Our example of the all-line axial analysis of the post-war Oosterwei neighbourhood in the Dutch town of Gouda shows that the shopping centre centrally located in the neighbourhood is poorly integrated in terms of visibility (Fig. 3.18 image (a)). At the shopping centre's front side, unemployed, low-skilled residents, and immigrants gather together. At the shop's backside, groups of adolescents with a migration background gather together. Along the sightlines with the highest

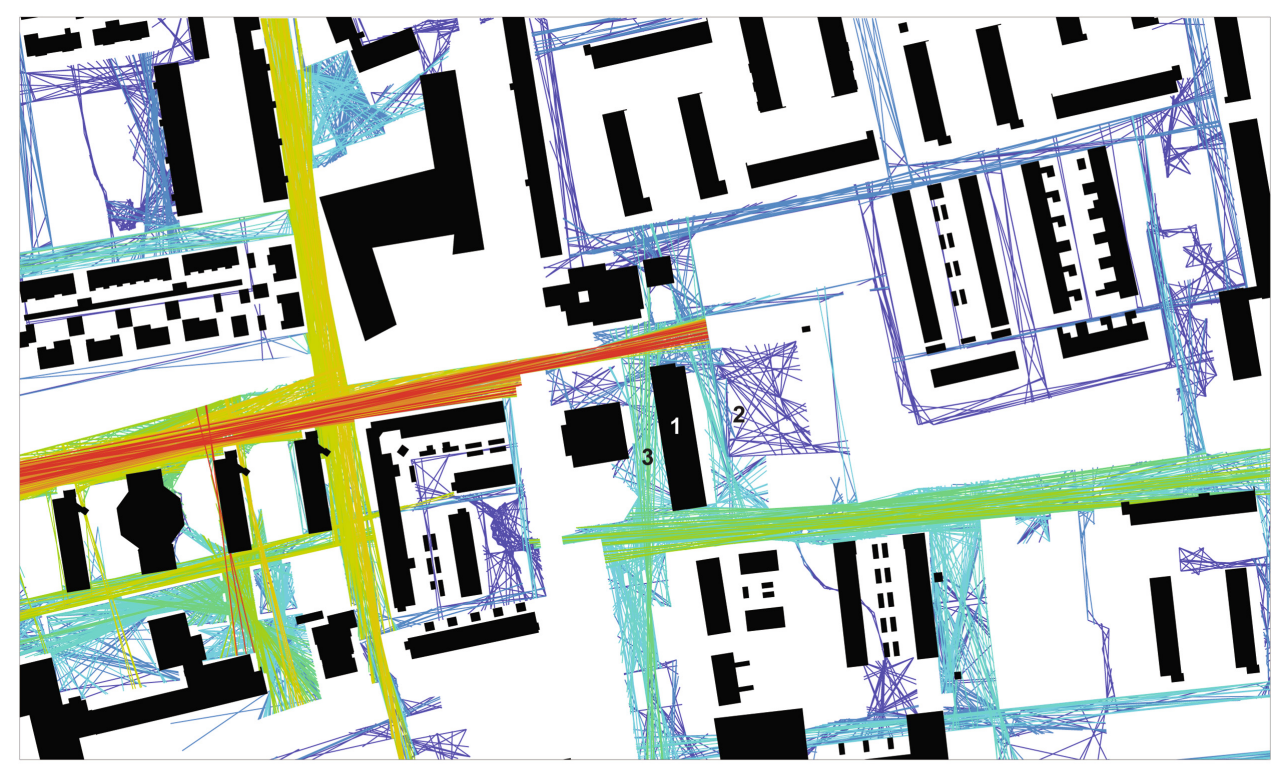

a) Oosterwei in Gouda

1: Shopping centre

2: Front side

3: Back side

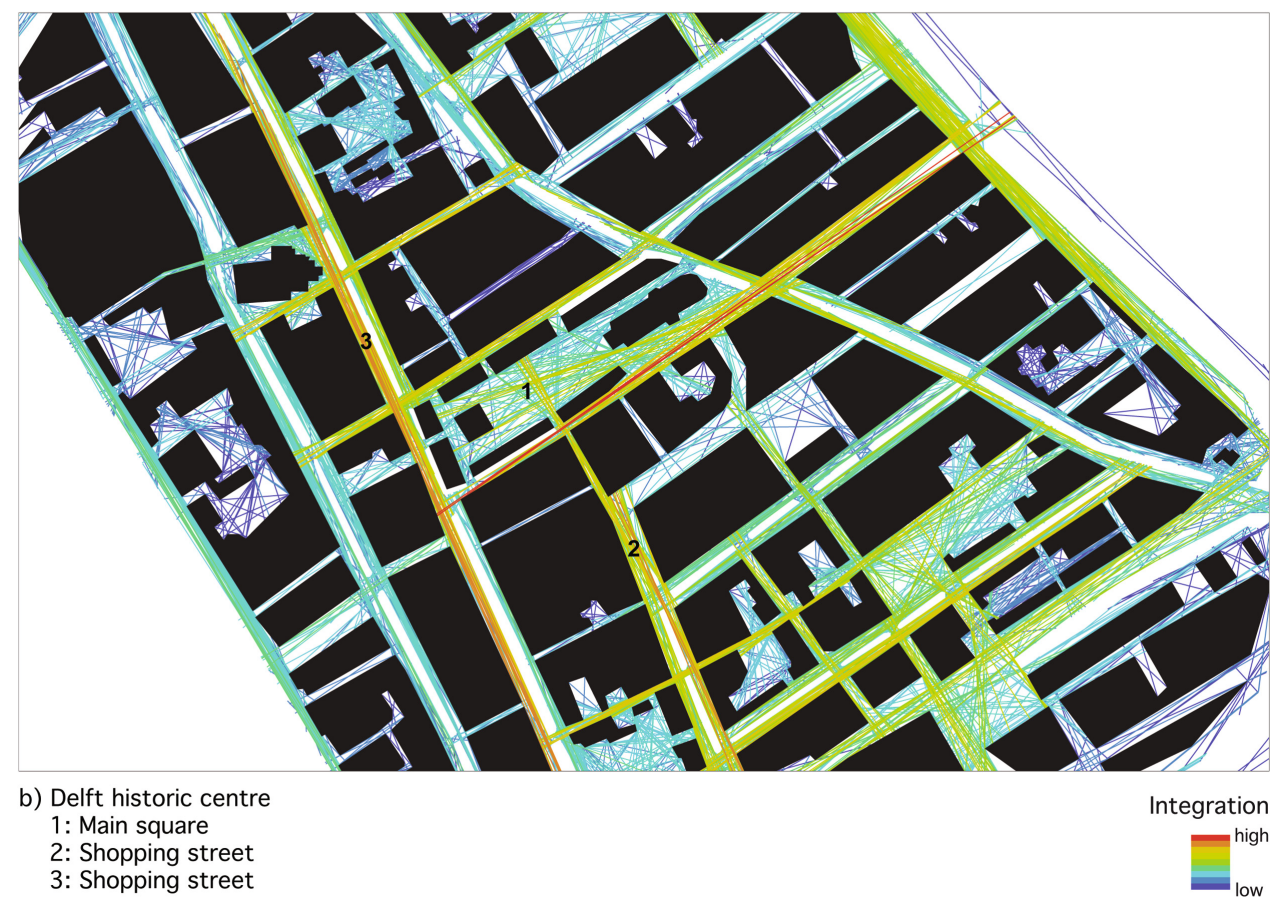

Fig. 3.18 All-line axial analysis for the neighbourhood of Oosterwei in Gouda (a), and the historic centre of Delft (b) in the Netherlands 
integration (indicated in red), a social mix of men, women, and children of either a native Dutch or a migration background are clustering. For the remaining areas, there is a divide between native and non-native social groups. Only a few woman and girls move through or carry out stationary activities in the segregated spaces (Rueb and van Nes 2009).

In Fig. 3.18, we show an all-line analysis for the historic centre in Delft. In many ways, making and processing an axial map is much faster than drawing the base map for the all-line analyses for the Delft case due to the narrow streets. This is the case for most old urban areas. However, the all-line analysis of Delft shows the spatial potentials for the pedestrian movement flow in all of the open spaces or squares of Delft. The main shopping streets are highlighted along the highest integrated sightlines.

\subsection{Agent-Based Modelling}

The principles of agent-based modelling using visual fields and syntactic steps are rooted in the research of Ruth Conroy Dalton in 2001. According to Dalton (2001), people tend to choose the root with the fewest angular deviations towards their destination (see also Chap. 2). Agent-based modelling as applied in the arena of space syntax is built upon this research. Herein, for the agent-based model, as a raster-based analysis, a certain number of agents equally distributed in the space under scrutiny for a certain time frame aggregate their movement routes. An agent's sight field can vary. Space syntax agent-based modelling analysis can be carried out using space syntax software applications.

In our example in Fig. 3.19, we compare three different scenarios for park X.

(a) The agent as an average person. Five thousand agents walk three syntactic steps, or move three cells forward, before making a decision about their direction change based on their sight field. This sight field is set at $15^{\circ}$. Results with these parameter settings comply with the registration of people's real-life movement routes through a certain built environment.

(b) The agent as a tourist. When enlarging the sight field angle to $30^{\circ}$ and reducing the syntactic steps to one, a different movement pattern occurs. All agents concentrate in the centre of park X. This is a typical movement pattern for tourists. Tourists are not familiar with the built environment they are in and want to explore it. Therefore, a strategic location with the longest views into the urban space is chosen.

(c) The agent as a local. When reducing the sight field angle to $7^{\circ}$ and increasing the number of syntactic steps to five, another movement pattern occurs. This is the movement pattern of locals. Locals are familiar with their neighbourhood and the city in general, and they have knowledge about which route to take to reach their destination efficiently. Their movement lines are straightened out, and they do not cluster in the centre of the park or public space.

The number of agents released, the number of syntactic steps, and the visual field can be adapted to any urban situation.

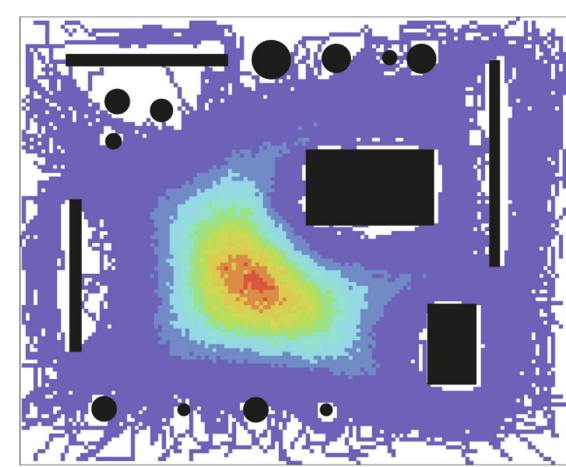

(a) $\mathrm{ABM}$ - the agent as an average person: sight field angle of 15 degrees and 3 steps before direction change

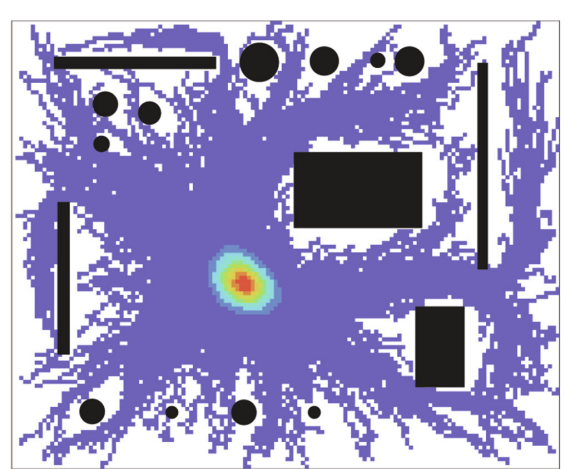

(b) $\mathrm{ABM}$ - the agent as a tourist: sight field angle of 30 degrees and 1 step before direction change

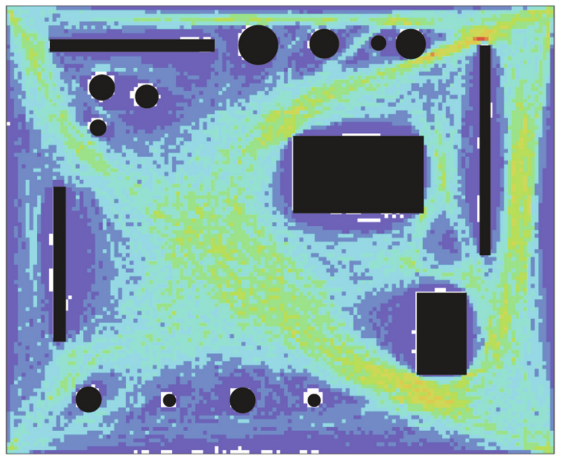

(c) ABM - the agent as a local: sight field angle of 7 degrees and 5 steps before direction change

$$
\begin{gathered}
\text { Number of agents } \\
\text { high low }
\end{gathered}
$$

Fig. 3.19 Three different parameter settings for an agent-based model for park X: (a) the agent as an average person, (b) the agent as a tourist, and (c) the agent as a local 
We applied this agent-based modelling logic to a neighbourhood of Siena's historic centre in Italy in Fig. 3.20. The parameter settings for the 'agent as an average person' depict both the movement routes of tourists and locals. Naturally, the result is a bit blurred because it covers both. The agent-based models for the agent as a tourist and a local illustrate the differences of their movement patterns. When comparing the results from the agent-based modelling with the results of the VGA and through vision analysis, the following can be stated: Tourists cluster in places where the largest integration of the through vision can be found, whereas locals move according to the results of an angular choice analysis. The reason for this is that tourists like to gather in places where they can get a large overview of the place they are visiting. In the case of Siena, this is the Piazza del Campo. The tourists like to gaze around and get an overview of the place and its buildings. Locals already know these artefacts. Therefore, the movement pattern of the locals has a clear origin and destination and can be classified mostly as necessary activities.

As an add-on, the space syntax software 'DepthmapX' enables one to trace the movement routes of agents individually. A perspective map with 3D agents can also be generated. We applied this to our example of Siena in Fig. 3.21. Our example depicts a group of agents released from the same location with a given time frame of $2 \mathrm{~min}$. The release spot for the agents was located where one street is leading into the Piazza del Campo. This application in the DepthmapX software allows one to understand how the agents orientate and navigate through space departing from the same location in the neighbourhood, and this analysis is useful for understanding the degree of orientability of an urban area from a certain strategic location. This can be, for example, the city gate, a metro stop, a train station, harbour ports, the entrance of a park, etc. 

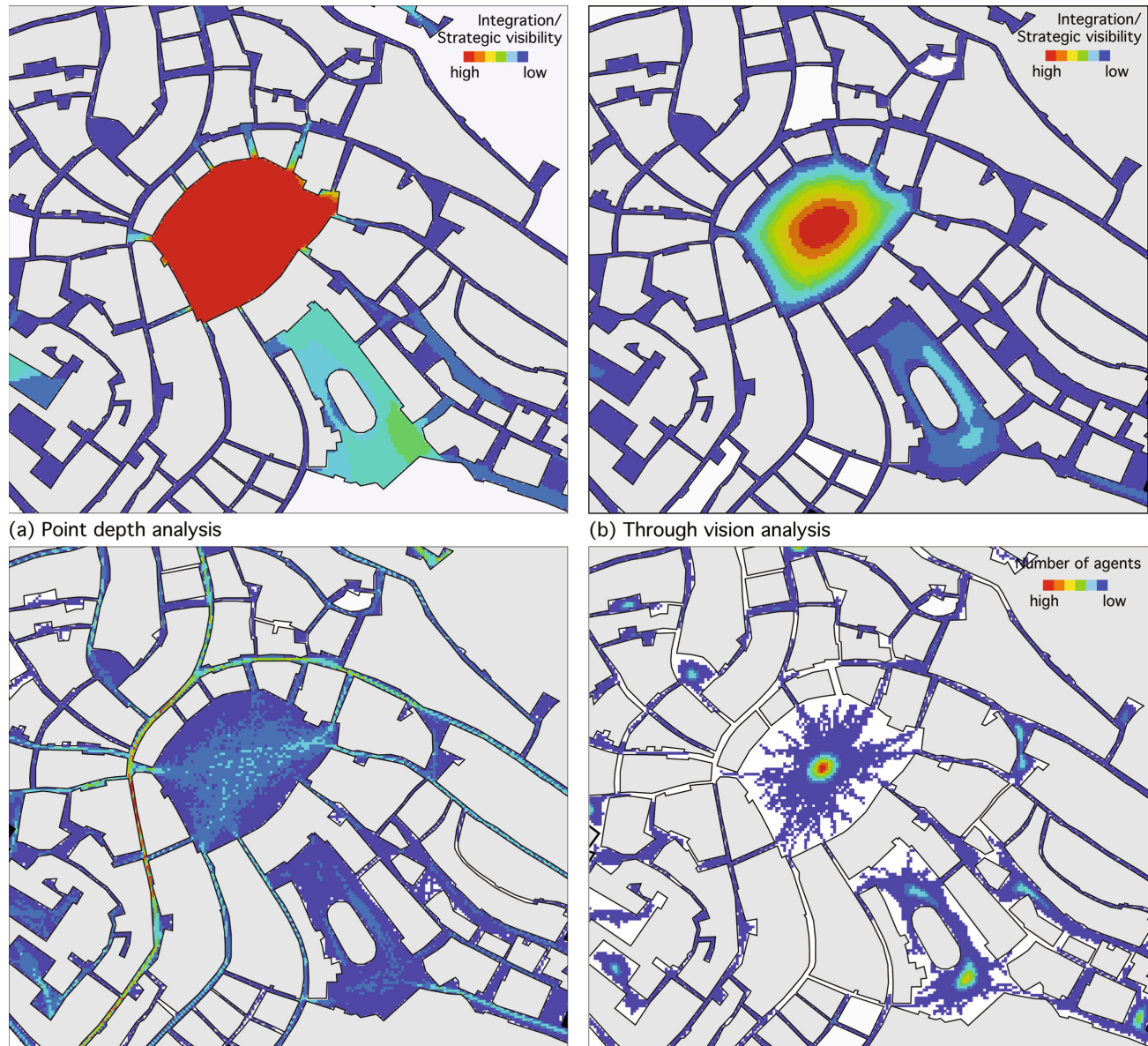

(c) Agent-based model: sight field angle 7 degrees, 5 steps
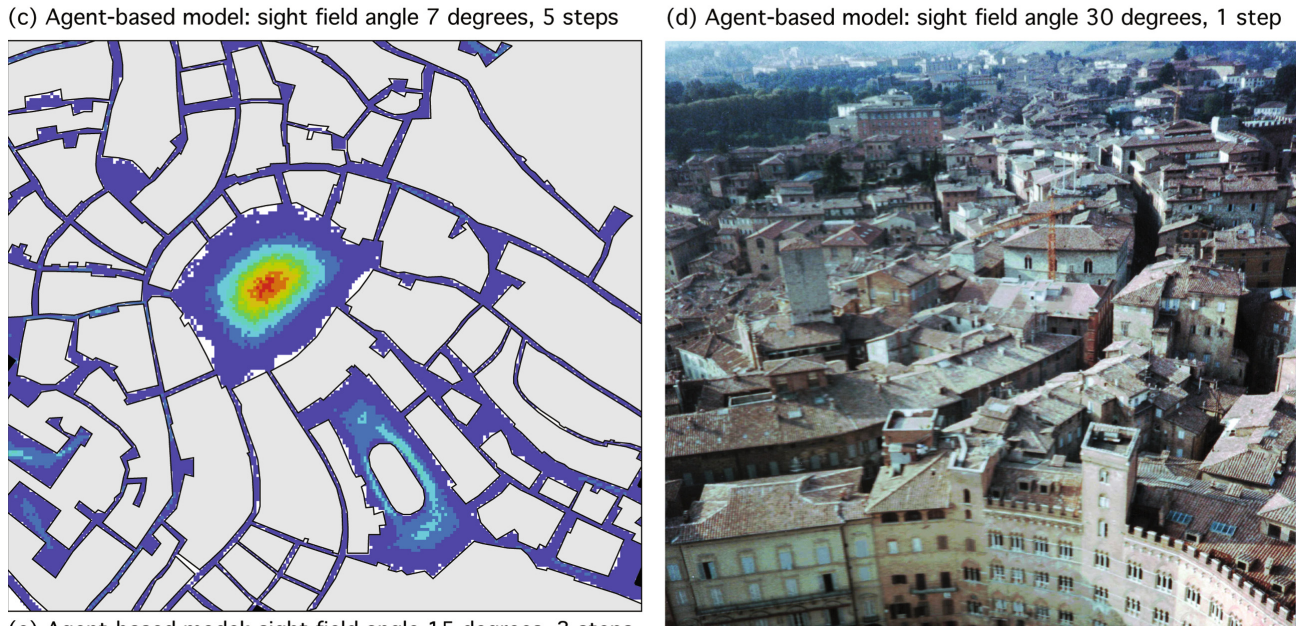

(e) Agent-based model: sight field angle 15 degrees, 3 steps

(e) Piazza del Campo

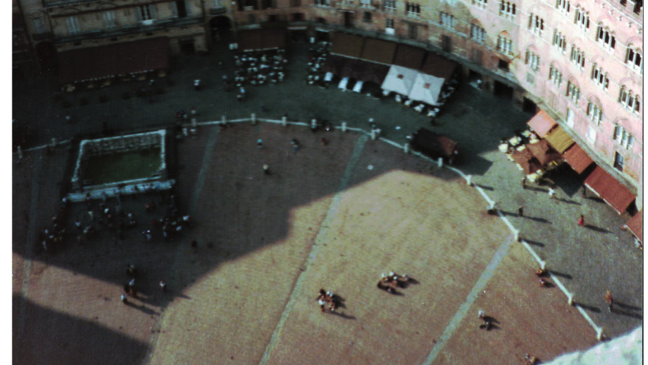

Fig. 3.20 Agent-based analysis and VGA for the central areas in Siena in Italy: (a) the point-depth analysis, (b) the through vision analysis, (c) the agent as a local, (d) the agent as a tourist, (e) the agent as an average person, and (f) an image of Siena's main square Piazza del Campo 

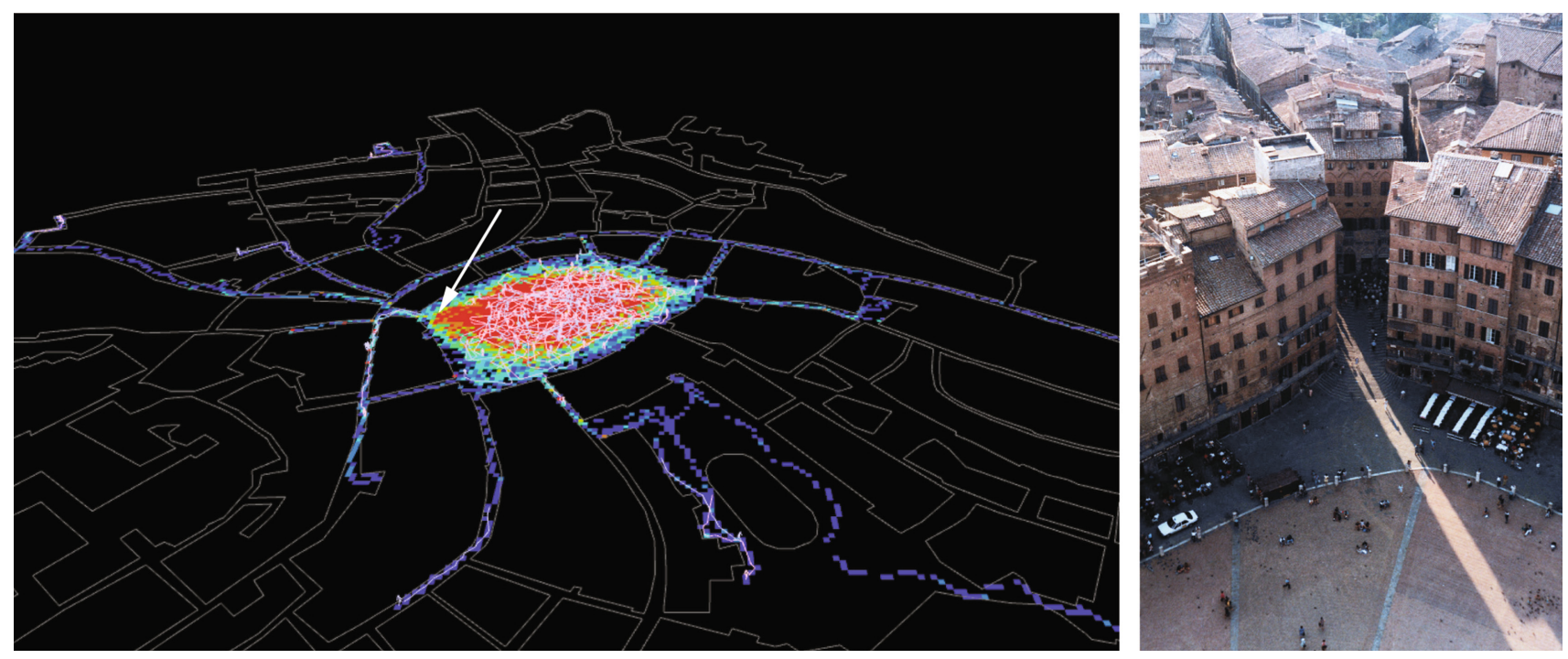

Fig. 3.21 Agent-based model from one point (left) and a picture of the location of the agent's starting point (right)

\subsection{Conclusion: Some Common Errors to Be Aware Of}

In its early stage, VGA was applied to buildings only. In particular for art galleries and museums, this analysis was useful for investigating the various degrees of orientation and wayfinding through the buildings and the accessibility and visibility for the most or least frequently visited collection items. Over the years, VGA has been applied for urban squares and neighbourhoods, which is possible due to on-going computer application development and increasing computation power.

There are some common errors and misuses to be aware of. When drawing or generating the base map for analysis in geographic information system software (GIS software) or AutoCAD, the novice modeller tends to forget to snap the ends of either the boundary line or the polygons representing urban blocks. Often the snapping tool is not activated. When generating the raster for the analysis, often a too coarse-grained raster contributes to the exclusion of narrow streets because their surfaces do not fully cover two-thirds of a cell's surface and are therefore dismissed. The VGA results will thus be inaccurate. Likewise, forgetting to add vegetation and fences to the base map will influence the analytical results of the visual graph, through vision, and all-line analyses.

VGA and all-line axial analysis calculate accessibility and visibility in parallel two-dimensionally, but how should one deal with soft spatial boundaries such as small ponds, grass fields, and flower beds? The rule is to represent these kinds of soft boundaries and include them in the model by outlining them in the base map. The reason for this is that we see them, but do not move across them-accessibility is more important than visibility.

The current challenge with the 2D VGA for urban areas is that it does not allow one to include several terrain levels like bridges and fly-overs at the same time. Many modern city centres like the Central Business District in Hong Kong are distributed among several levels. On-going development includes an efficient analytical tool for processing a 3D VGA (Bruyns et al. 2019). 


\subsection{Exercises}

\section{Exercise 1}

Manually generate an isovist from two different locations of a familiar urban square. Describe the differences between the two isovist fields. Do they overlap?

For the exercises below, you need to use computer software.

\section{Exercise 2}

Draw a polygon base map consisting of the outlines of buildings, vegetation, fences, etc. of a familiar neighbourhood or public square. You can use any computer software that allows exporting your base map file as a .dxf or .mif file. Process an all-axial line analysis map using the space syntax software 'DepthmapX'. Explain and interpret the results and how they relate to your own experience of the chosen area.

\section{Exercise 3}

Run a VGA from your previously drawn base map. What are the differences in the results from the visual graph, through vision, and connectivity analyses? Process a one-point step depth and several-point step depth analysis from the map. Explain and interpret the results.

\section{Exercise 4}

Run an agent-based model from the same base map. Experiment with different visual field angles and syntactic steps. Describe, explain, and interpret the results. Explain the following: How do the results of your agent-based model correlate with the results from the VGA, all-line axial analysis, and real life?

\section{Exercise 5}

Figure 3.22 illustrates a figure ground map of a park with a couple of trees. A concert organiser wants to place a music stage in the park. Where do you suggest placing the stage for a maximum number of seats for the audience and in such a way that every concertgoer has a good view of the stage. If you could remove one tree, which one would it be to increase the visibility for all and why? Choose a suitable analysis to present your suggestion as a 'before and after' situation. You can test various options.

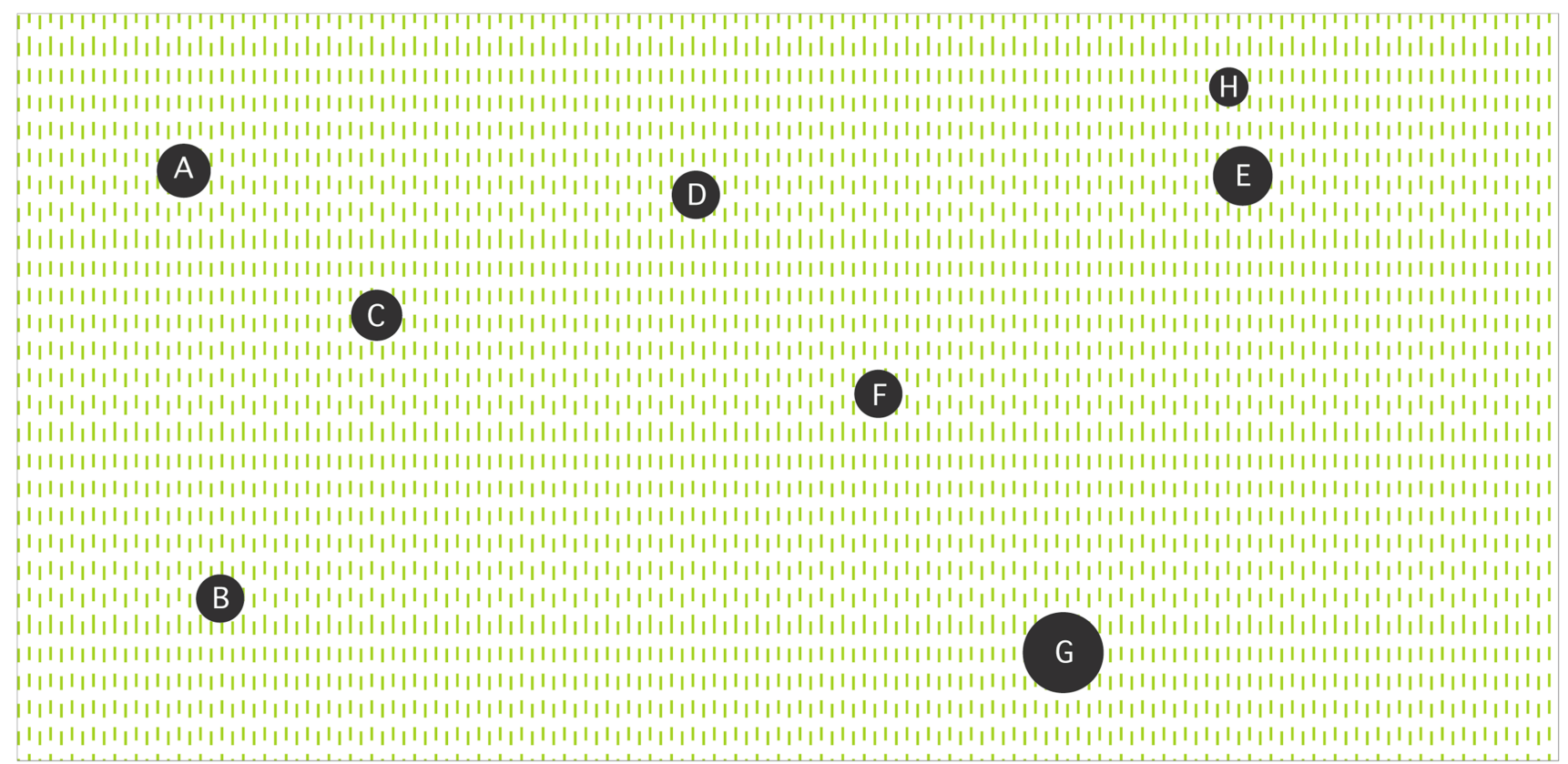

Fig. 3.22 A park with trees 


\subsection{Answers}

\section{Exercise 5}

The maximum number of seats can be gained by placing the stage at the bottom of the figure and removing tree ' $\mathrm{f}$ '.

\section{References}

Benedikt, M.L. 1979. To take hold of space: Isovists and isovist fields. Environment and Planning B: Planning and Design 6: 47-65.

Bruyns, G., D. Nel, C.D. Higgens, and A. van Nes. 2019. Flat versus volumetric methodologies. Restructuring spatial analysis and other indices In Proceedings of the 12th International Space Syntax Symposium, ed. by S. Qiang et al. Beijing: Beijing Jiao Tong University.

Conroy Dalton, R. 2001. The secret is to follow your nose. In Proceedings Space Syntax. 3rd International Symposium, Atlanta, ed. by J. Peponis, J. Wineman, and S. Bafna.

Culagovski, R., M. Greene, and R. Mora. 2014. Development of 3D VGA tools: An application in a case of weak heritage in Valparaiso, Chile. Ingenieria e Investigacion 34 (3): 31-36.

Cullen, G. 1971. The concise townscape. Oxford: Architectural Press.

Dalton, N. 2001. Fractional configurational analysis and a solution to the manhattan problem. In Proceedings Space Syntax. 3rd International Symposium, Atlanta, ed. by J. Peponis, J. Wineman, and S. Bafna.

Dalton, N., R. Conroy Dalton, P. Marshall, I. Peverett, and S. Clinch. 2015. Three dimensional isovists for the study of public displays. In Proceedings of the 10th International Space Syntax Symposium. Space Syntax Laboratory, ed. by K. Karimi, L. Vaughan, K. Sailer, G. Palaiologou, and T. Bolton. London: The Bartlett School of Architecture, UCL (University College London).

Fisher-Gerwitzmann, D., and I.A. Wagner. 2003. Spatial openness as a practical metric for evaluating built-up environments. Environment and Planning B: Planning and Design 30: 37-49.

Hillier, B. 1996. Space is the machine: A configurational theory of architecture. Cambridge: Cambridge University Press.

Hillier, B., and J. Hanson. 1984. The social logic of space. Cambridge: Cambridge University Press.

Hillier, B., and C.F. Shu. 2000. Crime and urban layout: The need for evidence. In Secure foundations. Key issues in crime prevention, crime reduction and community safety, ed. by S. Ballintyne, K. Pease, and V. McLaren. London: Institute for Public Policy Research.

Jacobs, J. 1960. The death and life of great American cities. New York: Random House.

Kim, G., A. Kim, and Y. Kim. 2019. A new 3D space syntax metric based on 3D isovist capture in urban space using remote sensing technology. Computers Environment and Urban Systems 74: 74-87.

Morello, E., and C. Ratti. 2009. A digital image of the city: 3D isovists in Lynch's urban analysis. Environment and Planning B: Urban Analytics and City Science 36 (5): 837-853.

Rueb, L., and van Nes. 2009. Spatial behaviour in Dutch dwelling areas. How housing layouts affects its users' behaviour. In Proceedings 7 th International Space Syntax Symposium, ed. by D. Koch, L. Markus, and J. Steen, Stockholm.

Space Syntax Laboratory. 1994. London Millennium Bridge. https://www.spacesyntax.com/projects/.

Space Syntax Laboratory. 2001. Trafalgar square. A world square for all. https://www.spacesyntax.com/Files/MediaFiles/Trafalgar_Profile.pdf.

Tandy, C.R.V. 1967. The isovist method of landscape survey. In Symposium: Methods of Landscape Analysis, ed. by H.C. Murray, 9-10. London: Landscape Research Group.

Teller, J. 2003. A spherical metric for the field-orientated analysis of complex urban open spaces. Environment and Planning B: Planning and Design 30: 339-356.

Trova, V., E. Hadjinikolaou, S. Xenopoulos, and J. Peponis. 1999. The structure of public space in sparsely urban areas. In Proceedings Space Syntax. 2nd International Symposium, Brasil, ed. by F. Holanda.

Turner, A. 2005. Could a road-centre line be an axial line in disguise. In Proceedings Space Syntax. 5th International Symposium, Delft, ed. by A. van Nes.

Turner, A. 2007. To move through space. Lines of vision and movement. In Proceedings Space Syntax. 6th International Symposium, Istanbul, ed. by A.S. Kubat.

Turner, A., et al. 2001. From isovists to visibility graphs: A methodology for the analysis of architectural space. Environment and Planning B: Planning and Design 28 (1): 103-121.

van Bilsen, A. 2009. How can serious games benefit from 3d visibility analysis. In ISAGA, editor, Proceedings of ISAGA 2009, Singapore.

van Bilsen, A., and E.H. Stolk. 2007. The potential of isovist-based visibility analysis. In The Architectural Annual 2005-2006, ed. by H.C. Bekering, J. Klatte, and D. Hauptmann, 68-73. Rotterdam: 010 Publishers.

Watts, D., and S. Strogatz. 1998. Collective dynamics of "small world" networks. Nature 4: 409-410.

Yamu, C., A. van Nes, C. Garau (2021). Bill Hillier's Legacy: Space Syntax-a synopsis of basic concepts, measures, and empirical application. Sustainability, 13(6): 3394. https://doi.org/10.3390/su13063394

\section{Further Readings}

Carmona, M., T. Heath, T. Oc, and S. Tiesdel. 2012. Public places-Urban spaces. Routledge.

Hillier, B. 1996. Space is the machine: A configurational theory of architecture. Cambridge: Cambridge University Press.

Hillier, B., and J. Hanson. 1984. The social logic of space. Cambridge: Cambridge University Press.

Jacobs, J. 1960. The death and life of great American cities. New York: Random House. 
Kim, G., A. Kim, and Y. Kim. 2019. A new 3D space syntax metric based on 3D isovist capture in urban space using remote sensing technology. Computers Environment and Urban Systems 74: 74-87.

LeGates, R.T., and F. Stout. 2011. The city reader, 5th ed. Routledge Urban Reader series.

Marshall, S. 2005. Streets and patterns. Oxon: Spon Press.

Yamu, C., A. van Nes, C. Garau (2021). Bill Hillier's Legacy: Space Syntax-a synopsis of basic concepts, measures, and empirical application. Sustainability, 13(6): 3394. https://doi.org/10.3390/su13063394

Open Access This chapter is distributed under the terms of the Creative Commons Attribution 4.0 International License (http://creativecommons. org/licenses/by/4.0/), which permits use, duplication, adaptation, distribution and reproduction in any medium or format, as long as you give appropriate credit to the original author(s) and the source, a link is provided to the Creative Commons license and any changes made are indicated.

The images or other third party material in this chapter are included in the work's Creative Commons license, unless indicated otherwise in the credit line; if such material is not included in the work's Creative Commons license and the respective action is not permitted by statutory regulation, users will need to obtain permission from the license holder to duplicate, adapt or reproduce the material. 